Article

\title{
Ecological Predictors of Older Adults' Participation and Retention in a Physical Activity Intervention
}

\author{
Manuela Peters ${ }^{1, *(D)}$, Tiara Ratz ${ }^{2}\left(\mathbb{D}\right.$, Frauke Wichmann $^{1}$, Sonia Lippke ${ }^{2}\left(\mathbb{D}\right.$, Claudia Voelcker-Rehage $^{3}$ \\ and Claudia R. Pischke 4 \\ 1 Leibniz Institute for Prevention Research and Epidemiology_BIPS, 28359 Bremen, Germany; \\ wichmann@leibniz-bips.de \\ 2 Department of Psychology \& Methods, Jacobs University Bremen, 28759 Bremen, Germany; \\ t.ratz@jacobs-university.de (T.R.); s.lippke@jacobs-university.de (S.L.) \\ 3 Department of Neuromotor Behavior and Exercise, Institute of Sport and Exercise Sciences, University of \\ Muenster, 48149 Muenster, Germany; claudia.voelcker-rehage@uni-muenster.de \\ 4 Institute of Medical Sociology, Centre for Health and Society, Medical Faculty, Heinrich Heine University \\ Duesseldorf, 40225 Duesseldorf, Germany; claudiaruth.pischke@med.uni-duesseldorf.de \\ * Correspondence: mpeters@leibniz-bips.de; Tel.: +49-(0)421-218-56924
}

check for updates

Citation: Peters, M.; Ratz, T.; Wichmann, F.; Lippke, S.; Voelcker-Rehage, C.; Pischke, C.R. Ecological Predictors of Older Adults' Participation and Retention in a Physical Activity Intervention. Int. J. Environ. Res. Public Health 2022, 19, 3190. https://doi.org/10.3390/ ijerph19063190

Academic Editors: Antonio Granero-Gallegos, María Carrasco-Poyatos and Ismael Ballesta García

Received: 19 February 2022

Accepted: 6 March 2022

Published: 8 March 2022

Publisher's Note: MDPI stays neutral with regard to jurisdictional claims in published maps and institutional affiliations.

Copyright: (C) 2022 by the authors. Licensee MDPI, Basel, Switzerland. This article is an open access article distributed under the terms and conditions of the Creative Commons Attribution (CC BY) license (https:// creativecommons.org/licenses/by/ $4.0 /)$.

\begin{abstract}
Research is still lacking regarding the question as to how programs to promote healthy ageing should be organized in order to increase acceptance and thus effectiveness. For older adults, ecological factors, such as the physical distance to program sites, might predict participation and retention. Thus, the key aim of this analysis was to examine these factors in a physical activity intervention trial. Adults $(N=8299)$ aged 65 to 75 years were invited to participate and $n=589$ participants were randomly assigned to one of two intervention groups with 10 weeks of physical activity home practice and exercise classes or a wait-list control group. Response, participation, and dropout data were compared regarding ecological, individual, and study-related variables. Kaplan-Meier curves and Cox regression models were used to determine predictors of dropout. In total, 405 participants completed the study. Weekly class attendance rates were examined regarding significant weather conditions and holiday periods. The highest rates of nonresponse were observed in districts with very high neighborhood levels of socioeconomic status. In this study, ecological factors did not appear to be significant predictors of dropout, whereas certain individual and study-related variables were predictive. Future studies should consider these factors during program planning to mobilize and keep subjects in the program.
\end{abstract}

Keywords: response; dropout; older adults; physical activity interventions; OSM; GIS

\section{Introduction}

Despite the strong evidence of physical and psychological health benefits of physical activity (PA) [1-3], PA remains a leading cause of morbidity and mortality worldwide [4]. As overall life expectancy has increased during the past decades, population-based approaches that target older people in fostering the maintenance of health-promoting behaviors, including regular moderate to vigorous PA, are called for [5]. Less than half of German older adults meet required PA levels [6] based on the recommendations provided by the World Health Organization (WHO) for adults aged 65 years and above [7]. Unfortunately, the majority of interventions fail to ensure that a physically active lifestyle and attendance of PA programs is maintained for extended periods of time [8]. Another challenge is to get the target group involved in intervention programs in the first place. Many researchers examining community-based programs for health promotion face difficulties in recruiting and retaining participants in their trials [9]. Certain barriers to recruitment may arise with respect to studies designed to involve older adults, such as issues around the identification 
of appropriate individuals and physical access. Non-respondents may systematically differ from respondents in certain baseline characteristics [10] (e.g., more health-conscious individuals may be more likely to self-select to PA programs and trials [11]). Keeping participants in research programs and thus obtaining an adequate amount of outcome data is another major challenge [10]. Attrition rates, in particular, in e-health interventions are high, ranging from $50-80 \%[10,12]$. Another point of concern is the possibility of selective dropout (e.g., higher attrition in either the intervention group (IG) or the control group (CG) [13]). Further, adherence to interventions is important for the intervention's impact on health outcomes. However, in addition to dropout and partial loss of participants, suboptimal recruitment that misses out the full range of the target population can be a problem as conclusions about the effectiveness of programs might be skewed. Also, corresponding research trials can cause biased results [14] and consequently impact the external validity of the study and the generalizability of the findings to the general population $[10,15]$. Thus, to increase the effectiveness of health interventions and to attract older adults to PA interventions and ensure completion of these programs, a better understanding of factors that act as barriers or facilitators for participation and retention are fundamental.

There are several factors known to affect participation and retention in PA intervention programs among older adults, including individual-level factors, ecological factors and those related to the study and program design [16,17]. A framework related to the social dimension is the socioemotional selectivity theory (STT) by Carstensen et al. which describes the relative importance and changes of personal life goals for different age groups, stating that older adults have more goals associated with emotions than younger age groups [18]. In its core, the theory posits that when lifetime limitations are perceived, present-oriented goals with emotional significance (e.g., intensifying social contacts) are prioritized over future-oriented goals, such as expanding individual knowledge. There are indications that psychosocial factors (including knowledge, beliefs, self-efficacy and social support) play a role in older adults' behavior, such as participation in interventions and adherence to community exercise classes [16]. Based on a systematic review, there is evidence suggesting health interventions may be particularly successful, if they are grounded in social cognitive models that address psychological factors such as the perceived barriers of preventative health behavior [19]. However, such models have been criticized for being better at predicting behavioral intention than actual behavior [19]. Therefore, it is important to consider a wider perspective regarding potential influencing factors. Thus, a broader theoretical basis for the multidimensional analysis presented in this article is based on socio-ecological approaches to promote active living, which consider the complex interrelations between individuals, social and physical environments, including organizational factors [20-22].

In the following, empirical evidence on the supposed individual and ecological factors influencing participation and retention is presented based on a literature review.

\section{Literature Review}

\subsection{Individual-Level Factors}

With respect to the overall uptake of PA and sports offerings, individual-level differences known to impact program participation and retention include socio-demographic $[23,24]$, health-related [25,26], physical and psychological factors [27,28]. Accordingly, women, individuals with higher education and income levels, individuals with better objective and self-reported health, and those who are already actively involved in PA and sports are more likely to participate [29-31].

Studies of older adults' specific requirements for PA interventions also revealed specific differences according to individual-level characteristics. For example, there is some evidence that particularly older individuals [31,32], as well as those with lower socioeconomic status (SES), and those who are overweight, or had poorer exercise habits in the past [24], are susceptible to non-participation. Other reasons described as barriers to participation are a lack of information, time and/or interest [33,34], mobility and travel issues/problems with (access to) transportation [34-36], health problems $[34,36]$ or being already sufficiently 
active [33]. Paralleling participation, women, higher educated adults [26,37] and those of older age $[25,26,37]$ are more likely to stay in programs. In addition, there are indications that men, in contrast to women, are more skeptical of engaging in group activities [38].

\subsection{Ecological Factors}

In line with social-ecological model approaches [20,39], there is a growing recognition of potentially relevant ecological factors influencing PA behavior in general, such as the physical and social environment [40]. In addition, evidence from systematic reviews suggests that ecological conditions affect participation in local sport offers and social activities of older people [3,41].

\subsubsection{Socioeconomic Composition of the Neighborhood}

The importance of integrating the geographical context into health research is exemplified by a considerable number of studies demonstrating associations of residence in a deprived neighborhood with lower levels of PA [42,43] or sports participation rates [44], while suffering from a higher number of health problems and health care inequalities [45]. Despite being in greater need, older adults in deprived areas are reported to have lower interest in participating in community-based activities associated with financial costs (e.g., for transport) [46] or have limited access to public transport and have, thus, trouble reaching certain facilities (e.g., facilities that exercise classes are held in) [47]. In addition, a small number of studies identified a greater risk of attrition in PA programs occurring in individuals living in areas with low and medium socioeconomic status $[23,48]$.

\subsubsection{Distance}

Due to the aging of societies, access to, and living in close proximity to, services of daily needs and health-related facilities is becoming increasingly important [41]. Along with distances, the effort associated with a claim in the sense of commuting times and costs must be taken into account. This is of crucial relevance, as this group is generally facing more financial and physical limitations than others.

Some studies have demonstrated the importance of accessibility and proximity of facilities for PA in general $[38,49]$, or indicated inaccessibility or lack of transport as barriers for engagement in exercise offers [50]. Given that with increasing age, individuals become more susceptible to large distances [51], inadequate access may prevent them from participation [46]. A qualitative study has highlighted proximity as an important element facilitating participation and retention in PA intervention studies, stating that participants who lived far away from the study sites or who moved far away during the study period were difficult to retain in the study [52]. Access to research sites is also a main concern often reported by older adults [53].

Research on older adults' participation in prevention classes found benefits of short distances to course locations [54,55] or, conversely, identified larger distances as a barrier, with decreased opportunities for usage and higher costs for transport [56]. Thus, a preference has been shown for classes that are in close proximity to reduce travel time and costs [17]. Basche et al. gathered specific reasons explaining why access and transport are a problem in that age group, e.g., worries about driving in bad weather and about the amount of time which must be spent to get to the study center [57]. Distance between a participant's home and the study site was also found to be a significant factor impacting enrolment and retention in a longitudinal aging study, with greater participation rates for closer distances and, in addition, higher dropout risk for increasing distances [58]. In a study by Farber et al., participation in daily or social activities was significantly reduced among older adults residing in car-dependent neighborhoods, e.g., those in the suburban or rural areas [59]. Consequently, a recent literature review revealed the implementation of studies close to the place of residence of the participants to be important for high retention rates [34].

However, the findings published to date are based on studies conducted in countries (such as the United States of America, with distance scales between 50 and 500 miles) 
that can neither be generalized nor transferred to other regions with different experiences depending on the social or cultural context. Regardless of the mode of transport, in Germany, $44 \%$ of daily trips are completed within ten minutes or less and around $70 \%$ take no longer than 20 min [60]. For European older adults, several studies found that women and those with a low income make fewer trips of shorter distances compared to younger populations, men, and those with higher earnings [61,62].

\subsubsection{Weather Conditions, Season and Holiday Periods}

According to the evidence of systematic reviews, the weather is an environmental factor affecting individuals' PA and mobility in day-to-day life [42,63]. Older adults are particularly more vulnerable to weather-related factors compared with younger age groups [64] and are more likely to change the way they go about their daily activities depending on the weather conditions [65]. Rainy, snowy and windy weather conditions, as well as conditions of extreme heat are assumed to prevent trips and cause daily activities to be postponed or avoided $[65,66]$. Moreover, precipitation can affect both active transportation, as well as motorized travel (car and public transport) [57,67].

A study on older, urban women and their attendance in an exercise class found adverse weather conditions, such as heat, wind chill, and snowfall in the hours before the class to be associated with a lower likelihood of attendance [68]. Furthermore, the authors noted a negative impact of the daily number of sunlight hours, assuming the class attendance to be substituted by other outdoor activities in warmer seasons [68]. These findings are supported by a longitudinal study in older US-American adults on the effect of weather indicating cold and snowy weather to be highly associated with a decreased exercise class attendance rate [69]. In addition, in a Canadian qualitative study, 30\% of participants reported harsh weather conditions, especially winter weather, as a barrier to participation in exercise classes [70]. Nevertheless, similar to the results regarding the distances, the evidence of the cited studies is not transferable to the German context due to different climatic conditions.

Furthermore, instructor- or design-related factors and organizational determinants (such as program characteristics, time, location/setting) have been previously identified as playing a role when it comes to retention of participants [17,31,71].

Finally, seasonality might affect day-to-day planning and PA behaviors through weather variations as well as individual arrangements of leisure time. For example, public holidays or school breaks may encourage grandparents to take care of their grandchildren. Accordingly, a study investigating older adults' decisions to stop participation in a resistance training program reported holidays as one of the three main contributing factors for withdrawal [72].

In sum, research, particularly regarding ecological determinants of older adults' participation in and dropout from PA interventions, is still limited and there are almost no findings for German settings. This is a major shortcoming, because older adults have a higher prevalence of co-morbidities and disabilities than the general population, which is generally associated with lower adherence [73]. Thus, three study aims are formulated for this article:

(1) To determine whether the findings regarding individual-level factors associated with reduced participation and retention available thus far can be supported by the present study, which enrolled older German adults.

(2) To identify ecological predictors and program-related determinants of overall participation and retention. Consideration will be given to the socioeconomic composition and setting (urban vs. suburban) of the participant's neighborhood, as well as the proximity to intervention sites.

(3) To determine associations of concise weather exposures and (public) holidays with weekly attendance rates in scheduled exercise classes. 


\section{Materials and Methods}

\subsection{Data and Procedures}

\subsubsection{Intervention Program}

In this study, we used data originating from a community-based intervention trial conducted from May 2016 to November 2017 in the Bremen-Oldenburg metropolitan region in Germany. The study is part of the larger research network "Physical Activity and Health Equity: Primary Prevention for Healthy Ageing" (AEQUIPA) [74]. A detailed description of the study design, including inclusion and exclusion criteria, recruitment and randomization strategies and the intervention has been reported elsewhere [75,76]. Briefly, older adults, aged 65 to 75 years, living independently (without assisted living), drawn from the residents registration office (RRO) from five communities representing areas of low community readiness regarding PA programs for older adults [77], were invited to participate in a three-month randomized controlled PA trial via mail.

During the study, the inclusion criterion of age was slightly expanded from 65 to 75 years to 60 to 80 years to allow for an inclusion of eligible partners or spouses of potential participants of a different age in the study. The size of the sample randomly selected in respective communities was proportional to the resident target population and was balanced by gender (1:1). The sample size calculation is described in detail in the published study protocol [76]. Reminders were sent out in cases of no response after two weeks. In addition to this main recruitment strategy, the study was also publicized in local newspaper articles with the option to call up the research team directly. Individuals were excluded from the study if they had already planned vacation during the intervention period, had certain medical conditions, severe health impairments, or had no PC/internet access.

Participants were randomly assigned to either a web-based intervention with subjective PA self-monitoring (IG1), a web-based intervention with subjective and objective PA selfmonitoring (IG2) or a waitlist control group (CG) [76]. Participants in the IGs completed an identical 10-week (week two to eleven) program engaging in weekly on-site trainerlead PA group sessions for $90 \mathrm{~min}$. They were encouraged to continue exercising at home, using web-based program material, and to monitor their PA with a web-based PA diary (both IGs) and an activity-tracker (only IG2). The CG was offered the intervention of IG1 after completion of the follow-up assessment, but without weekly group meetings. Study participants received questionnaires at the study sites at baseline (week one) and follow-up assessments (week twelve) and were asked to return them within one week via mail.

\subsubsection{Ecological Data}

To evaluate the neighborhood level context, data for the administrative units were derived from the statistical offices of Bremen and the state of Lower Saxony, Germany. To measure the impact of proximity, the points of interest (POIs), such as residential addresses of participants, as well as study sites (where baseline and follow up assessments took place in week one and twelve) and intervention sites (with onsite classes in week two to eleven) were geocoded and, in addition, assigned to administrative units (districts). The roads data (linear features such as roads and footpaths) were extracted from Open Street Maps (OSM) via QGIS 3.2.3 (QGIS Development Team), OSM Plugin (Quick OSM, Version 1.5, QGIS Development Team). Daily accurate local weather data were recorded from publicly accessible databases maintained by the German Weather Service/Climate Data Center (CDC) [78]. In addition, national public holidays and local school breaks for the years 2016 and 2017 in Bremen and Lower Saxony (Germany) were retrieved from the website schulferien.org [79] in September 2021. Table 1 shows the types of data resources used. 
Table 1. Assessed characteristics and data sources.

\begin{tabular}{|c|c|c|c|c|}
\hline \multirow[b]{2}{*}{$N$} & \multicolumn{2}{|c|}{ Response } & \multicolumn{2}{|c|}{$\begin{array}{l}\text { Dropout from the Study and Attendance in Weekly } \\
\text { Onsite Classes }\end{array}$} \\
\hline & Characteristics & Data Source & Characteristics & Data Source \\
\hline \multirow{7}{*}{ Individual level } & Age & Registration office & Age & Telephone interviews \\
\hline & Gender & Registration office & Gender & Telephone interviews \\
\hline & Residential address & Registration office & Residential address & Registration office \\
\hline & & & Level of education & Questionnaire \\
\hline & & & Employment status & Questionnaire \\
\hline & & & Household income & Questionnaire \\
\hline & & & Perceived health & Questionnaire \\
\hline \multirow{7}{*}{ Ecological level } & Neighborhood SES & Statistical offices ${ }^{1}$ & Neighborhood SES & Statistical offices ${ }^{1}$ \\
\hline & \multirow{3}{*}{ Proximity } & Geocoded home addresses & \multirow{3}{*}{ Proximity } & Geocoded home addresses \\
\hline & & Geocoded study center & & Geocoded intervention sites \\
\hline & & OSM street network data & & OSM street network data \\
\hline & & & Weather $^{2}$ & GWS/CDC \\
\hline & & & Season & Study Data \\
\hline & & & Public/school holidays 2 & schulferien.org \\
\hline
\end{tabular}

Note: ${ }^{1}$ of Bremen and Lower Saxony, ${ }^{2}$ only used to evaluate participation in the ten weekly onsite classes, CDC: Climate Data Center, GWS: German Weather Service, SES: socioeconomic status, OSM: Open Street Maps.

\subsection{Measures}

\subsubsection{Primary Outcomes}

For the analysis, the primary outcomes were the study's response, participation and dropout rates. Response rate was defined as the number of responders in relation to the number of invited individuals. Participation rate was defined as the number of participants, including volunteers, who were included in the study after screening for eligibility in relation to the number of invited ones. Dropout rate was defined as the number of participants indicating that they were not willing or able to continue the program, in proportion to those who joined the intervention. In addition, attendance rates in weekly onsite classes, recorded by the respective assigned leaders, were calculated.

\subsubsection{Potential Explanatory Variables}

District Level Socio Economic Status

For a district assignment and classification regarding urban and suburban neighborhoods, the participants' zip codes were used. Because the use of established composition indices for assessing regional socioeconomic deprivation hardly revealed any heterogeneity in our data and that they are, in addition, prone to prevent the detection of differential correlations [80], we used data on the number (proportion) of welfare recipients from the welfare statistics as a proxy. Data were divided into quartiles scaled to the distribution of all administrative units in the study region with the first quartile (Q1) reflecting lowest and the fourth quartile (Q5) reflecting highest neighborhood SES.

\section{Proximities to Interventions Sites}

The network analysis tool in QGIS 3.2.3. (QGIS Development Team) was used to calculate the distance between respondents' georeferenced home locations and georeferenced study and intervention sites. The latter varied depending on the community (Figures 1 and 2). To ensure a routable network, all POIs needed to be snapped properly to the network, something which was not the case in the initial data set. Therefore, they were matched via QGIS snapping tools to the closest vertices (nodes, junctions, road bends) of 
the street network [81]. Using the street network data, proximities based on the shortest possible path were measured. The most appropriate geographic scales regarding older adults' PA and mobility in health and planning research are still unknown [82]. Therefore, the choice of cut-offs for five distance categories started with thresholds for walkable distances commonly used in built environment and health research, which represent an approximate walk time between (or up to) $10 \mathrm{~min}(800 \mathrm{~m})$ and $20 \mathrm{~min}(1600 \mathrm{~m})$ [83,84].

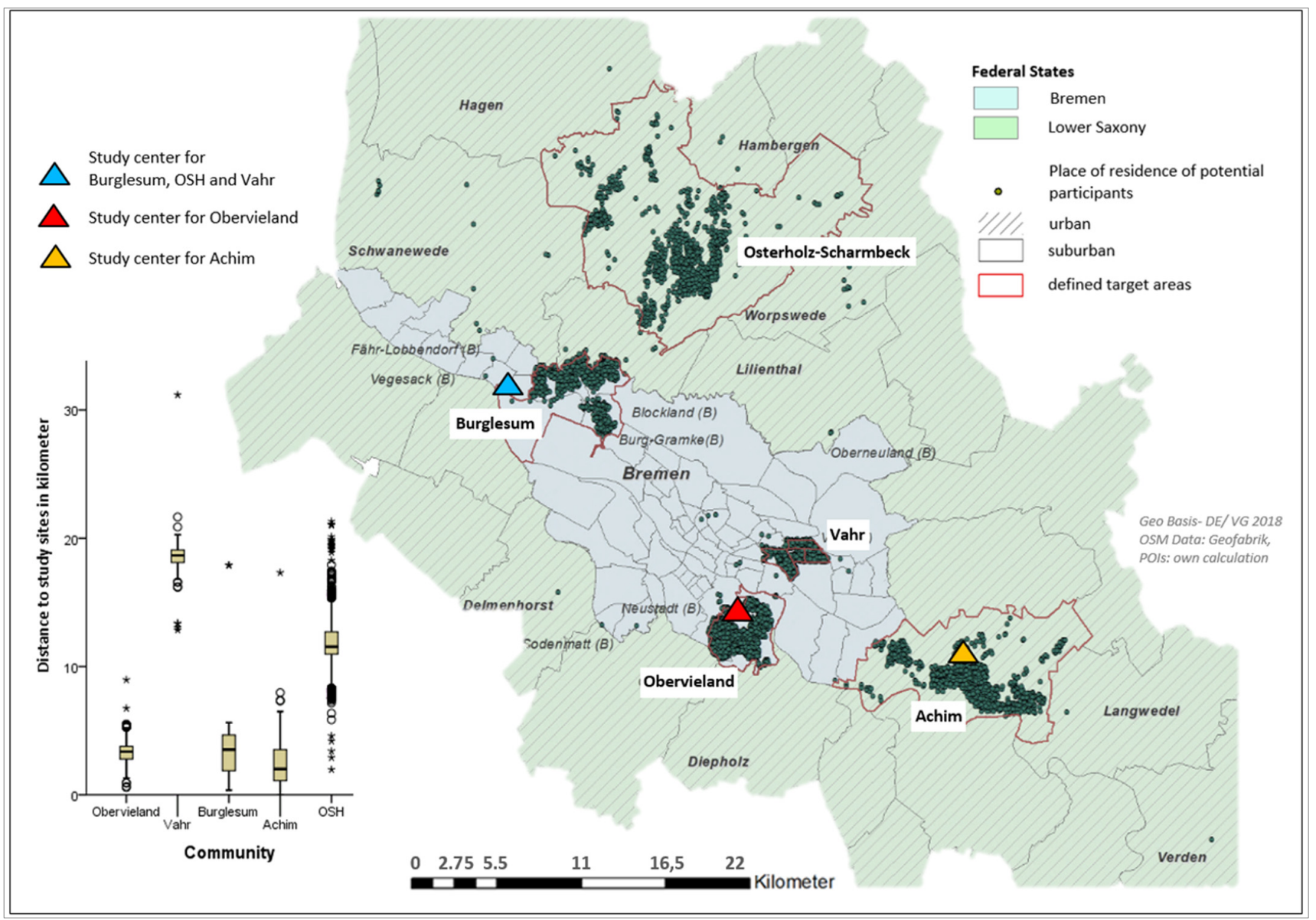

Figure 1. Invited participants in the recruitment sample by target area and communities, and distance to the study centers (where baseline and follow-up assessments took place in week one and twelve). Note: OSH: Osterholz-Scharmbeck, * individual outliers within the Boxplot.

As participants' geocoded homes were blurred for data protection reasons following a method described elsewhere [85], the real coordinates are slightly shifted. Following the methodology, home coordinates in low populated areas (based on the number of inhabitants) are moved by a larger factor than in densely populated areas, which particularly affects participant residences located in more distant, suburban areas. As the distance categories become broader in the upward direction (greater proximities), the study centers (not the participants' blurred home addresses) were set as the starting point for the distance measures to compensate for the potential shift bias term.

\section{Weather, Season, Public and School Holidays}

The weather data (including total rainfall, mean temperature, and wind speed) were selected and classified according to the threshold of significant weather exposures defined by the German Weather Service (GWS) [86]. As the study continuously recruited participants in various recruitment waves and participants were assigned to different groups, the weather on the days of the group sessions within each of the 10 weeks of the onsite classes 
differed between the groups. We examined whether significant weather for temperature (in degree Celsius above 30 or below zero), rainfall (>15 1/ $\mathrm{m}^{2}$ within an hour) and/or wind speed $(>7$, which is $60 \mathrm{~km} / \mathrm{h}$ ) was present on the days under consideration, using binary dummy variables $(\mathrm{YES}=1 / \mathrm{NO}=0)$.

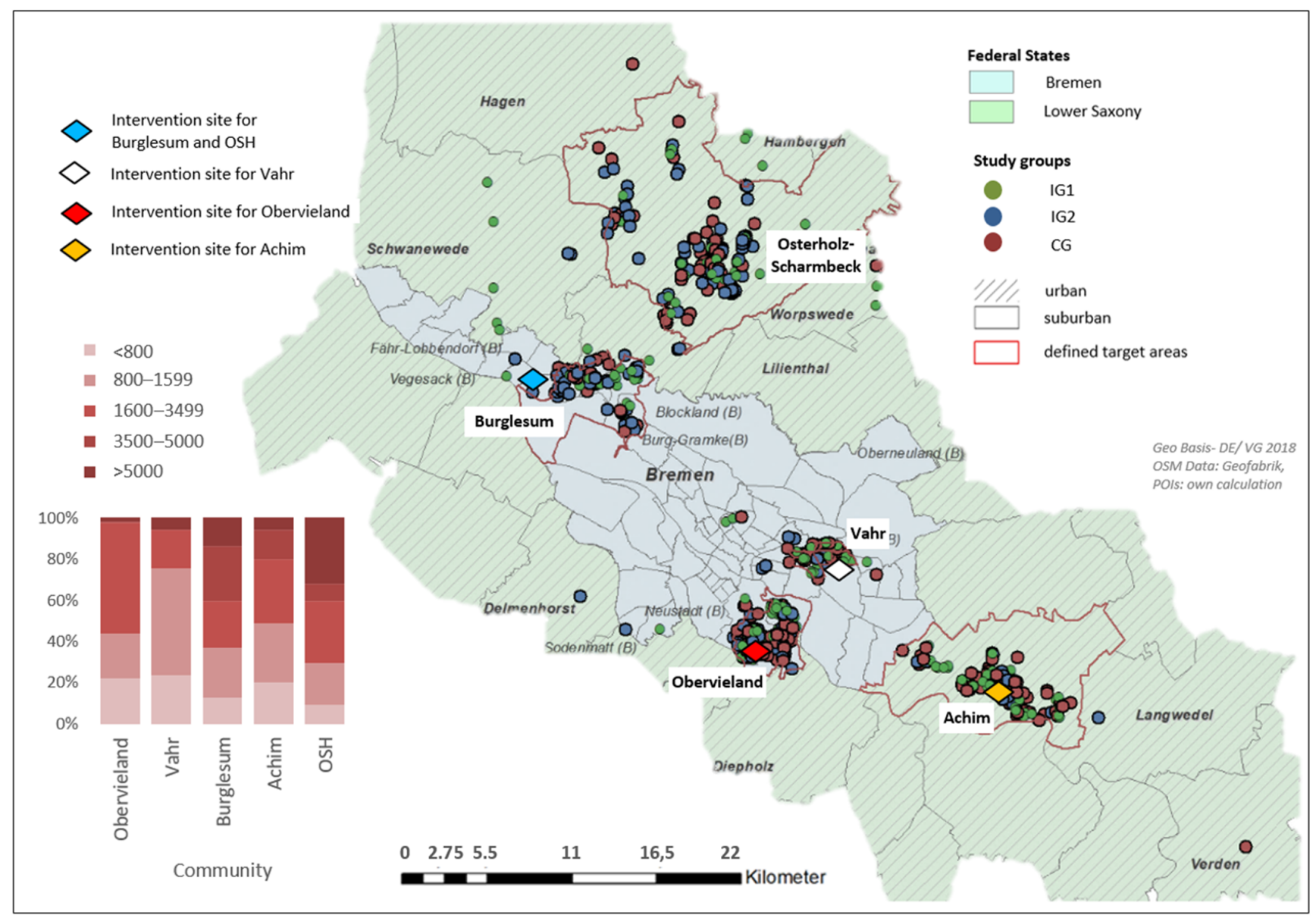

Figure 2. Participants of study $(n=589)$ by target area, communities and distance to the intervention sites (where onsite classes took place from week two to eleven). Note: OSH: Osterholz-Scharmbeck.

To account for the effect of season, the variables winter (December through February), spring (March through May), summer (June through August), and autumn (September through November) were coded.

Public holidays in Germany (e.g., Labor Day, German Unity Day, Reformation Day, Ascension Day, Whit Monday, and Easter Monday, etc.) were considered if a given class day was the day before, the day of, or the day after the holiday. Additionally, information was collected on whether the respective intervention period occurred during school breaks.

\section{Individual-Level Characteristics}

Of the individuals who were included in the study, and for whom a dropout analysis was calculated, age and gender were obtained during the initial telephone interview, and data on education level, employment status, household income and self-rated health (subjective) status were collected during the baseline assessment via questionnaire. Level of education was coded following the 2011 version of the International Standard of Education (ISCED), e.g., individuals with a higher educational status received a higher score (range 1-8) [87]. This was further dichotomized into low / moderate (ISCED 1 to 4) and high (ISCED 5 to 8) levels of education. Employment status was assessed using one item from a questionnaire for assessing demographic and socio-structural characteris- 
tics [88]. Household income was assessed using items of the German Health Interview and Examination Survey for Adults [89]. Need-weighted income per capita was derived considering the monthly household income and the number of individuals living in the household according to the German Microcensus [90]. The variable was then tertiled into low, middle, and high household income. Health status was assessed by asking older adults to rate their general health status using an item from the Short Form-36 Health Survey [91].

\subsection{Statistical Analysis}

Where the data were available, the analysis explored differences in individual and ecological participant characteristics between responders, non-responders, participants finally included in the study (according to the eligibility criteria) where available, as well as dropouts and completers. Descriptive statistics were summarized as number of cases with percentages for categorical variables, as well as the mean and standard deviation, as appropriate. In order to assess significant group differences between dropouts and completers, all categorical variables were compared by using the Pearson chi-square and Cramer's V tests. Attendance in onsite classes was calculated as the ratio of the number of actually present participants to the number of expected participants, considering dropouts. Because we did not track individual attendance in classes, this analysis could only be performed at the group level.

An appropriate method to assess predictive values for dropout is survival and Coxregression analysis [10], which includes a time-to-event variable. Ecological, as well as person-based data described above, served as basis for a descriptive analysis plotted as Kaplan-Meier curves to visualize the time until dropout by predictor variables. The equality of the survivor functions was tested with a log-rank test $(p<0.05)$. Survival analysis was performed to examine predictors of dropout among participants who started the intervention. The total number of weeks (1-12) was used as time variable for the event (dropout). Cox Proportional Hazards models were calculated to investigate the effects of potential predictors on dropout.

Age, gender, community, neighborhood setting (urban/suburban), intervention group, level of education, employment status, household income, subjective health, district level SES, distance to intervention sites and recruitment characteristics (contacted vs. volunteering persons) were first examined within a univariate (unadjusted) Cox proportional hazard regression. Predictors that showed noticeable differences regarding the relative hazard for dropout (hazard ratio, HR) were selected for inclusion in a multivariate (adjusted) regression model, even if they did not confirm to be significant $(p<0.05)$. The latter was tested in a stepwise backward procedure by sequentially excluding variables with $p$-values $\geq 0.05$ based on the likelihood ratio statistics. Finally, variables that significantly $(p<0.05)$ predicted dropout were kept in the final model. HRs and their $95 \%$ confidence intervals were calculated, and the Wald test was used for model testing.

Only participants with full data sets of all covariates to be studied $(n=539)$ were included in multiple regression models. Statistical analyses were performed using SPSS, IBM version 25 for Windows [92]. All spatial analyses described above were completed using QGIS, Version 3.2.3. for Windows (QGIS Development Team).

\section{Results}

\subsection{Results Regarding Participant Enrollment}

A random sample of $N=8299$ older adults was invited to participate in the study via mail, with 6694 not responding to the invitation letter and 598 proactively declining to participate. Men responded slightly less than women (81\% vs. $76.6 \%$ nonresponse). The total non-response rate was $80.7 \%$. For 220 individuals, the reason for exclusion was "death/address unknown". During the assessment for eligibility during the initial telephone interviews, an additional 373 potential participants were excluded for not meeting the inclusion criteria (see Figure 3). A total of 459 (77.9\%) contacted older adults were included 
in the study. Additionally, of 175 people who reacted to the press release and decided to participate in the study, 130 were eligible for inclusion. Finally, 589 study participants were randomized to the study groups: IG1 $(n=211)$, IG2 $(n=198)$ and CG $(n=180)$.

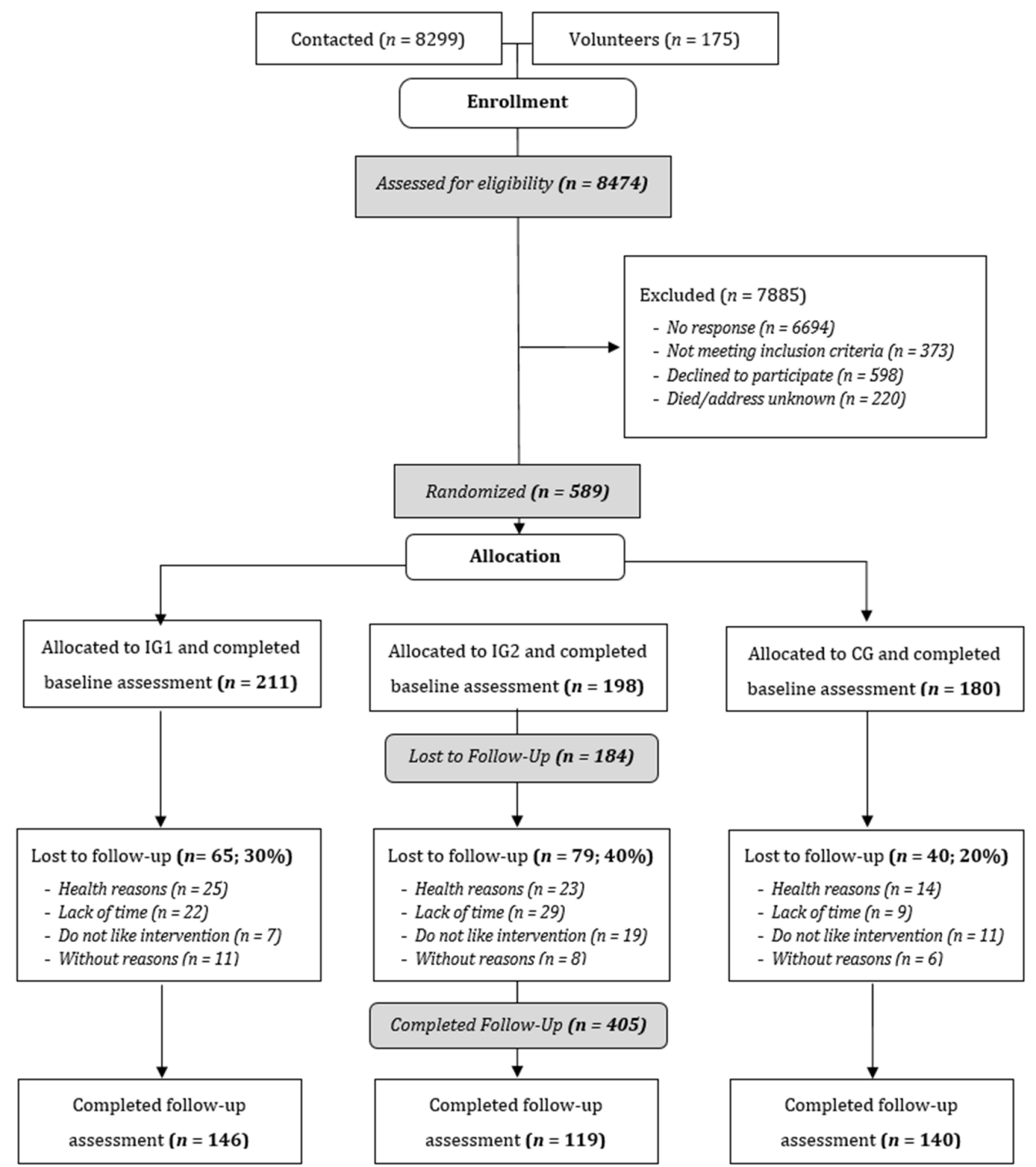

Figure 3. Flow chart. Note: CG: waitlist control group, IG1: web-based intervention with subjective PA self-monitoring, IG2: web-based intervention with subjective and objective PA self-monitoring.

Table 2 presents the characteristics of non-participants (non-responders as well as responders and volunteers who were not eligible for the study) and participants. There was no substantial difference in gender and setting (urban/suburban) towards response. In total, the districts with very high community levels of SES had the largest number of non-responders $(84.4 \%)$ based on the number of individuals contacted in that quartile in contrast to the lowest non-response rate from districts with the lowest SES (76.8\% of individuals contacted). The non-response rate with respect to the different communities varied from $75.5 \%$ (Osterholz-Scharmbeck) to $82.3 \%$ (Vahr) of the contacted persons in the given community. Most of the included (eligible) participants came from the community Obervieland (28.7\%) and the fewest from the community Vahr (14.4\%). Further, the majority of participants were retired $(77.1 \%)$, female $(58 \%)$, with low or moderate educational status 
(52.3\%), with a good health status (56.6\%), with high household income (34.5\%), and resided in districts with low level of SES (62.1\%).

\subsection{Results Regarding Retention}

Between the years 2016 and 2017, a total of 589 participants started the intervention. Finally, $n=405$ participants (69\%) completed the follow-up assessment after 12 weeks (IG1, $n=146$; IG2, $n=119 ; \mathrm{CG}, n=140$ ). IG2 displayed the greatest loss-to-follow up (Figure 3). Overall, the mean age of the included study participants was 71.4 years $(\mathrm{SD}=3.3)$ with higher, but non-significant dropout rates among the youngest and oldest age groups, women, volunteers, those with a lower household income, and those with the shortest and highest distances to intervention sites.

In total, the highest dropout rate appeared in those with higher SES at the district level $(p<0.05)$. There were significant $(p<0.01)$ variations between the different communities regarding the dropout rates (Table 2 ).

In addition, this analysis revealed that lower educated older adults $(p<0.05)$, those who reported less good or poor health $(p<0.01)$, and those who lived in urban neighborhoods $(p<0.01)$ were more likely to drop out. Although the study participation occurred in the spring/summer for the vast majority of participants, proportionally fewer participants that started the program in the fall/winter dropped out $(p<0.01)$.

\subsection{Survival Analysis and Stage of Dropout}

The Kaplan-Meier curves in Figures 4 and 5 show the participants' time until dropping out of the study. Overall dropout rates, starting with the baseline assessment (week 1), continuing with an introductory event (week 2), followed by ten weeks of the program, and ending with the follow-up assessment (week 12), indicate that between the fifth and sixth week, half of the dropout population had left the study, with the largest decrease occurring in the first week (Figure 5). Median survival time (the point at which $50 \%$ of the participants were still adherent) could also be directly read from the Kaplan-Meier curve (Figure 4). Of those who dropped out $(n=184)$, most of the attrition occurred within the first $(n=37,6.3 \%)$ and the ninth week $(n=29,4.9 \%)$.

In the group comparisons studied regarding time until dropout, men stayed longer in the intervention than women and were more likely to stay during the first week (Figure 5A). In addition, there were some significant differences according to the log-rank test. For example, participants in the control group remained in the intervention longer than those in IG1 and particularly IG2 $(p<0.01)$ (Figure 5C). Those who reported less good health $(p<0.01)$ (Figure 5D), living in districts with a high level of SES $(p<0.05)$ (Figure 5E) or reported a low or moderate level of education $(p<0.05)$ (Figure $5 \mathrm{G}$ ) left the study the earliest. Figure $5 \mathrm{~F}$ illustrates a high dropout in the first week among those from the community Vahr, something that can probably be attributed to the large distance to the study center in which the baseline assessments were performed during the first week (Figure 1).

This is supported by the Cox Proportional Hazards analysis presented in Table 3, indicating these factors as significant predictors $(p<0.05)$ in the univariate model. The HR of dropping out was 2.1 times higher for participants living in districts with high levels of SES compared with the HR for those in low SES districts (HR = 2.143, 95\% CI 1.299-3.536, $p<0.01)$. In addition, those who were randomized to IG2 were significantly more likely to drop out $(\mathrm{HR}=2.057,95 \%$ CI 1.406-3.009, $p<0.01)$. Some factors significantly decreased the HR of dropping out, such as being highly educated $(-32 \%, p<0.05)$, living in suburban areas $(-32 \%, p<0.05 \%)$, living in high distances to intervention sites $(3500-5000 \mathrm{~m})$ as compared with the shortest distance $(-30 \%, p<0.05)$. However, the results regarding the distances do not indicate a trend in the sense of increasing or decreasing dropout rates with increasing or decreasing distances. 


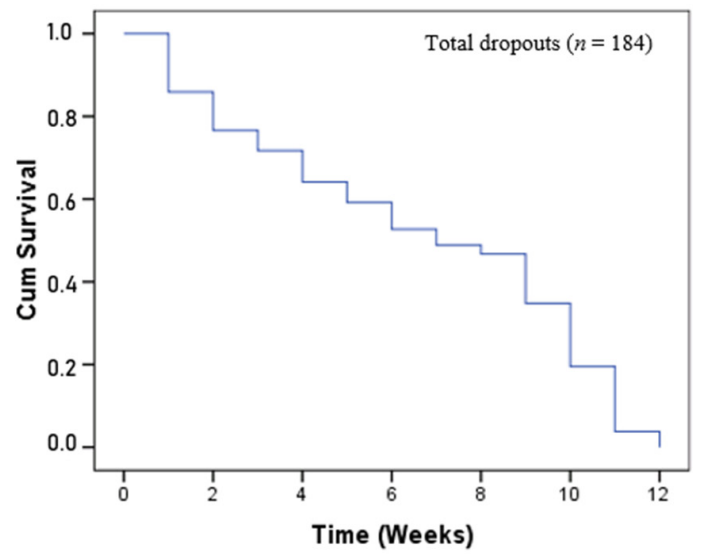

\begin{tabular}{lcccccccccccc} 
Week & $\mathbf{1}$ & $\mathbf{2}$ & $\mathbf{3}$ & $\mathbf{4}$ & $\mathbf{5}$ & $\mathbf{6}$ & $\mathbf{7}$ & $\mathbf{8}$ & $\mathbf{9}$ & $\mathbf{1 0}$ & $\mathbf{1 1}$ & $\mathbf{1 2}$ \\
\hline Remaining & 552 & 541 & 533 & 517 & 498 & 488 & 479 & 463 & 434 & 415 & 407 & 405 \\
participants, $n$ & 37 & 11 & 8 & 16 & 19 & 10 & 9 & 16 & 29 & 19 & 8 & 2 \\
Dropouts, $n(\%)$ & $(6.3)$ & $(2)$ & $(1.4)$ & $(2.7)$ & $(3.3)$ & $(1.7)$ & $(1.5)$ & $(2.7)$ & $(4.9)$ & $(3.2)$ & $(1.4)$ & $(0.3)$ \\
Cumulative dropout, & 37 & 48 & 56 & 72 & 91 & 101 & 110 & 126 & 155 & 174 & 182 & 184 \\
$n(\%$ of participants) & $(6.3)$ & $(8.3)$ & $(9.7)$ & $(12.4)$ & $(15.7)$ & $(17.4)$ & $(18.9)$ & $(21.6)$ & $(26.5)$ & $(29.7)$ & $(31.1)$ & $(31.4)$ \\
$\begin{array}{l}\text { Cumulative dropout, } \\
\% \text { of dropouts }\end{array}$ & 20 & 26 & 30 & 39 & 49 & 55 & 60 & 68 & 84 & 95 & 99 & 100
\end{tabular}

Figure 4. Time until dropout within 12 weeks for those who left the study $(n=184)$. Week 1 : baseline assessment one week before start of the intervention, week 12: follow up assessment following the intervention, weeks 2-11: intervention program.
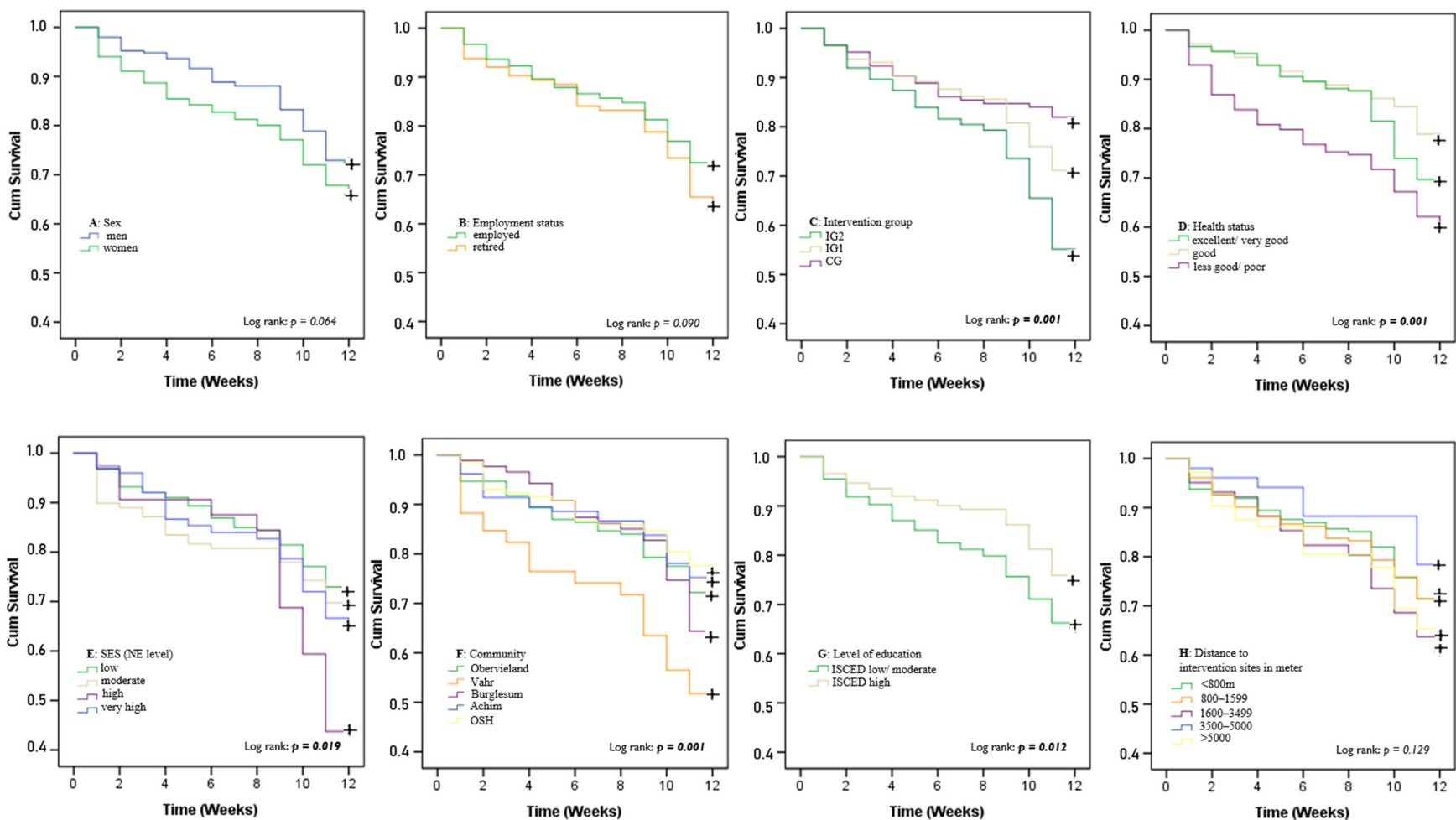

Figure 5. Survival plots for the time until dropout from the study comparing different variables ( $\mathrm{A}=$ sex, $\mathrm{B}=$ employment status, $\mathrm{C}=$ intervention group, $\mathrm{D}=$ health status, $\mathrm{E}=\mathrm{SES}, \mathrm{F}=$ community, $\mathrm{G}=$ level of education, $\mathrm{H}=$ distance to intervention sites). Note: $\boldsymbol{T}_{\text {censored data }}=$ end of observation period (week twelve). 
Table 2. Individual and community level characteristics.

\begin{tabular}{|c|c|c|c|c|c|c|c|}
\hline Characteristics & Contacted and Volunteers & Non-Responders * & Included Participants & Completed Study ** & Dropouts ** & $p$ & $\mathbf{V}$ \\
\hline$N$-Total (\%) & 8474 & 6694 & $589(7 \%)$ & $405(68.8)$ & $184(31.2)$ & & \\
\hline \multicolumn{8}{|l|}{ Recruitment, $n(\%)$} \\
\hline Contacted & 8299 & $6694(80.7)$ & 459 (77.9) & $324(70.6)$ & $135(29.4)$ & 0.072 & 0.074 \\
\hline Volunteers & 175 & & $130(22.1)$ & $81(62.3)$ & $49(37.7)$ & & \\
\hline \multicolumn{8}{|l|}{ Community $n(\%)$} \\
\hline Burglesum (urban) & $1085(12.8)$ & $855(78.8)$ & $87(14.8)$ & $55(63.2)$ & $32(36.8)$ & 0.002 & 0.172 \\
\hline Vahr (urban) & $2300(27.1)$ & $1892(82.3)$ & $85(14.4)$ & $44(51.8)$ & $41(48.2)$ & & \\
\hline Obervieland (urban) & $2257(26.6)$ & $1734(76.8)$ & $169(28.7)$ & $121(71.6)$ & $48(28.4)$ & & \\
\hline OSH (suburban) & $1457(17.2)$ & $1100(75.5)$ & $143(24.3)$ & $108(75.5)$ & $35(24.5)$ & & \\
\hline Achim (suburban) & $1375(16.2)$ & $1109(80.7)$ & $105(17.8)$ & $77(73.3)$ & $28(26.7)$ & & \\
\hline \multicolumn{8}{|l|}{$\begin{array}{c}\text { Neighborhood Settings, } n \\
(\%)\end{array}$} \\
\hline Urban & $5642(66.6)$ & $4481(79.4)$ & $341(57.9)$ & $220(64.5)$ & $121(35.5)$ & 0.009 & 0.107 \\
\hline Suburban & $2832(33.4)$ & $2209(78.4)$ & $248(42.1)$ & 185 (74.6) & $63(25.4)$ & & \\
\hline Missing & & 4 & & & & & \\
\hline Age in years, mean $(S D)$ & & & $71.4(3.3)$ & $71.3(3.2)$ & $71.6(3.5)$ & & \\
\hline $60-64$ & & & $5(0.8)$ & $3(60)$ & $2(40.0)$ & 0.552 & 0.060 \\
\hline $65-69$ & & & $196(33.3)$ & $136(69.4)$ & $60(30.6)$ & & \\
\hline $70-74$ & & & $305(51.8)$ & $215(70.5)$ & $90(29.5)$ & & \\
\hline $75-80$ & & & $80(13.6)$ & $50(62.5)$ & $30(37.5)$ & & \\
\hline Missing & & & $3(0.5)$ & $1(33.3)$ & $2(66.7)$ & & \\
\hline \multicolumn{8}{|l|}{ Gender, $n(\%)$} \\
\hline Male & $4146(48.9)$ & $3376(81.4)$ & $251(42)$ & $182(72.5)$ & $69(27.5)$ & 0.096 & 0.069 \\
\hline Female & $4328(51.1)$ & $3314(76.6)$ & $336(58)$ & $223(66.1)$ & $114(33.9)$ & & \\
\hline \multicolumn{8}{|l|}{ Season, $n(\%)$} \\
\hline Fall/winter & & $1872(28)$ & $165(28)$ & $135(81.8)$ & $30(18.2)$ & 0.001 & 0.176 \\
\hline Spring/summer & & $4822(72)$ & $424(72)$ & $270(63.7)$ & $154(36.3)$ & & \\
\hline \multicolumn{8}{|l|}{ Level of education, $n(\%)$} \\
\hline ISCED low, moderate & & & $308(52.3)$ & $201(65.3)$ & $107(34.7)$ & 0.019 & 0.098 \\
\hline ISCED high & & & $261(44.3)$ & $194(74.3)$ & $67(25.7)$ & & \\
\hline Missing & & & $20(3.4)$ & $10(50)$ & $10(50)$ & & \\
\hline
\end{tabular}


Table 2. Cont.

\begin{tabular}{|c|c|c|c|c|c|c|c|}
\hline Characteristics & Contacted and Volunteers & Non-Responders * & Included Participants & Completed Study ** & Dropouts ** & $p$ & $\mathbf{V}$ \\
\hline \multicolumn{8}{|l|}{ Employment status, $n(\%)$} \\
\hline $\begin{array}{l}\text { Employed or retired but } \\
\text { working }\end{array}$ & & & $113(19.2)$ & $71(62.8)$ & $42(37.2)$ & 0.070 & 0.076 \\
\hline Retired or other & & & $454(77.1)$ & $325(71.6)$ & $129(28.4)$ & & \\
\hline Missing & & & $22(3.7)$ & $9(41)$ & $13(59)$ & & \\
\hline \multicolumn{8}{|l|}{ Household income, $n(\%)$} \\
\hline Low & & & $164(27.8)$ & $109(66.5)$ & $55(33.5)$ & 0.299 & 0.067 \\
\hline Middle & & & $168(28.5)$ & $118(70.2)$ & $50(29.8)$ & & \\
\hline High & & & $203(34.5)$ & $150(73.9)$ & $53(26.1)$ & & \\
\hline Missing & & & $54(9.2)$ & $28(51.9)$ & $26(48.1)$ & & \\
\hline \multicolumn{8}{|l|}{ Subjective health status $n(\%)$} \\
\hline Excellent or very good & & & $144(24.5)$ & $116(80.6)$ & $28(19.4)$ & 0.001 & 0.188 \\
\hline Good & & & $333(56.6)$ & $234(70.3)$ & $99(29.7)$ & & \\
\hline Less good or poor & & & $87(14.7)$ & $46(52.9)$ & $41(41.1)$ & & \\
\hline Missing & & & $25(4.2)$ & $9(39)$ & $16(64)$ & & \\
\hline \multicolumn{8}{|l|}{ District level SES, $n(\%)$} \\
\hline First quartile (low) & $3779(44.6)$ & $2904(76.8)$ & $366(62.1)$ & $262(71.6)$ & $104(28.4)$ & 0.011 & 0.138 \\
\hline Second quartile (moderate) & $1911(22.6)$ & $1509(79)$ & $109(18.5)$ & $76(69.7)$ & $33(30.3)$ & & \\
\hline Third quartile (high) & $625(7.4)$ & $482(77.1)$ & $32(5.4)$ & $14(43.8)$ & $18(56.3)$ & & \\
\hline Fourth quartile (very high) & $2102(24.8)$ & $1774(84.4)$ & $75(12.7)$ & $49(65.3)$ & $26(34.7)$ & & \\
\hline Missing & $57(0.7)$ & $25(43.8)$ & $7(1.2)$ & $4(57.1)$ & $3(42.9)$ & & \\
\hline \multicolumn{8}{|l|}{$\begin{array}{l}\text { Distance to intervention sites } \\
\text { in meters, } n(\%)\end{array}$} \\
\hline$<800$ (very low) & & & $102(17.3)$ & $62(60.8)$ & $40(39.2)$ & 0.118 & 0.112 \\
\hline 800-1599 (low) & & & $161(27.3)$ & $115(71.4)$ & $46(28.6)$ & & \\
\hline 1600-3499 (moderate) & & & $203(34.5)$ & $143(70.4)$ & $60(29.6)$ & & \\
\hline 3500-5000 (high) & & & $51(8.7)$ & $40(78.4)$ & $11(21.6)$ & & \\
\hline >5000 (very high) & & & $72(12.2)$ & $45(62.5)$ & $27(37.5)$ & & \\
\hline Missing & & & & & & & \\
\hline
\end{tabular}

Note: $* \%$ from contacted in that category $* * \%$ from included in the category, $p=$ chi square-test group differences (completer/dropouts), with those in bold type indicating significan values, V = effect size by Cramer's V, ISCED: International Standard of Education, OSH: Osterholz-Scharmbeck, SES: socioeconomic status. 
Table 3. Results of univariate and multivariate Cox Regression $(N=539)$. Notes: * Tested in a stepwise backward procedure by sequentially excluding variables with $p$-values $\geq 0.05,{ }^{* *}$ Removed from multivariate models due to high correlation with the community variable (see Supplementary Figure S1). Bold marks indicate significant results.

\begin{tabular}{|c|c|c|c|c|c|c|}
\hline Characteristics & $\begin{array}{c}\text { Univariate HR (SE), } \\
95 \% \mathrm{CI}\end{array}$ & $p$ & $\begin{array}{l}\text { Multivariate HR Beginning } \\
\text { Model (SE), 95\% CI }\end{array}$ & $p$ & $\begin{array}{l}\text { Multivariate HR Final } \\
\text { Model * (SE), 95\% CI }\end{array}$ & $p$ \\
\hline \multicolumn{7}{|l|}{ Community } \\
\hline Obervieland (urban) & Reference & 0.001 & Reference & 0.011 & Reference & 0.003 \\
\hline Burglesum (urban) & $1.278(0.228), 0.817-1.998$ & 0.283 & $1.258(0.282), 0.724-2.187$ & 0.415 & $1.356(0.252), 0.828-2.221$ & 0.226 \\
\hline Achim (suburban) & $0.923(0.238), 0.579-1.407$ & 0.735 & $0.671(0.308), 0.367-1.227$ & 0.195 & $0.777(0.265), 0.426-1.306$ & 0.341 \\
\hline OSH (suburban) & $0.837(0.222), 0.541-1.293$ & 0.422 & $0.663(0.295), 0.372-1.120$ & 0.163 & $0.816(0.235), 0.515-1.295$ & 0.388 \\
\hline \multicolumn{7}{|l|}{ Intervention Group } \\
\hline IG1 & $1.437(0.201), 0.696-2.130$ & 0.072 & $1.770(0.232), 1.123-2.790$ & 0.014 & 1.149 (0.229), 1.149-2.822 & 0.010 \\
\hline IG2 & $2.057(0.194), 1.406-3.009$ & 0.001 & $2.767(0.223), 1.786-4.286$ & 0.001 & $2.666(0.219), 1.737-4.093$ & 0.001 \\
\hline \multicolumn{7}{|l|}{ Level of education } \\
\hline Low/moderate & reference & & reference & & reference & \\
\hline High & $0.683(0.156), 0.503-0.927$ & 0.014 & $0.693(0.171), 0.495-0.969$ & 0.032 & $0.674(0.165), 0.488-0.931$ & 0.017 \\
\hline \multicolumn{7}{|l|}{ Subjective health status } \\
\hline Excellent or very good & reference & 0.292 & reference & 0.001 & reference & 0.001 \\
\hline Good & $0.852(0.195), 0.581-1.250$ & 0.414 & $1.692(0.224), 1.092-2.623$ & 0.019 & $1.658(0.222), 1.072-2.563$ & 0.023 \\
\hline \multicolumn{7}{|l|}{ Employment status } \\
\hline Employed or retired but working & reference & & reference & & & \\
\hline Retired or other & $0.745(0.178), 0.526-1.056$ & 0.098 & $0.772(0.190), 0.532-1.120$ & 0.173 & & \\
\hline \multicolumn{7}{|l|}{ District level SES } \\
\hline First quartile (low) & reference & 0.027 & reference & 0.854 & & \\
\hline Second quartile (moderate) & $1.116(0.200), 0.754-1.651$ & 0.583 & $0.813(0.258), 0.490-1.349$ & 0.424 & & \\
\hline Third quartile (high) & $2.143(0.255), 1.299-3.536$ & 0.003 & $0.909(0.358), 0.451-1.832$ & 0.789 & & \\
\hline Fourth quartile (very high) & $1.253(0.219), 0.815-1.926$ & 0.304 & $0.987(0.299), 0.544-1.758$ & 0.978 & & \\
\hline \multicolumn{7}{|l|}{ Gender } \\
\hline Male & reference & & reference & & & \\
\hline Female & 1.319 (0.153), 0.978-1.778 & 0.070 & $1.212(0.137), 0.863-1.702$ & 0.267 & & \\
\hline
\end{tabular}


Table 3. Cont.

\begin{tabular}{|c|c|c|c|c|c|c|}
\hline Characteristics & $\begin{array}{l}\text { Univariate HR (SE), } \\
95 \% \mathrm{CI}\end{array}$ & $p$ & $\begin{array}{l}\text { Multivariate HR Beginning } \\
\text { Model (SE), 95\% CI }\end{array}$ & $p$ & $\begin{array}{l}\text { Multivariate HR Final } \\
\text { Model * (SE), 95\% CI }\end{array}$ & $p$ \\
\hline \multicolumn{7}{|c|}{$\begin{array}{c}\text { Distance to intervention sites in } \\
\text { meters }\end{array}$} \\
\hline$<800$ (very low) & reference & 0.150 & reference & 0.297 & & \\
\hline 800-1599 (low) & $0.696(0.216), 0.455-1.063$ & 0.093 & $0.670(0.246), 0.414-1.087$ & 0.105 & & \\
\hline 1600-3499 (moderate) & $0.726(0.204), 0.486-1.083$ & 0.117 & $0.858(0.237), 0.539-1.367$ & 0.520 & & \\
\hline 3500-5000 (high) & $0.493(0.341), 0.253-0.962$ & 0.038 & $0.771(0.389), 0.360-1.652$ & 0.503 & & \\
\hline >5000 (very high) & $0.951(0.249), 0.583-1.549$ & 0.839 & $1.216(0.299), 0.677-2.184$ & 0.513 & & \\
\hline \multicolumn{7}{|l|}{ Neighborhood setting ** } \\
\hline Urban & reference & & & & & \\
\hline Suburban & $0.676(0.155), 0.498-0.917$ & 0.012 & & & & \\
\hline \multicolumn{7}{|l|}{ Age (years) } \\
\hline $60<65$ & reference & 0.548 & & & & \\
\hline $65<70$ & $0.873(0.719), 0.213-3.572$ & 0.850 & & & & \\
\hline $70<75$ & $0.850(0.715) .0 .209-3.450$ & 0.820 & & & & \\
\hline $75<80$ & 1.131 (0.730). 0.270-4.735 & 0.866 & & & & \\
\hline \multicolumn{7}{|l|}{ Recruitment } \\
\hline Volunteers & 1.312 (0.167), 0.946-1.820 & 0.103 & & & & \\
\hline \multicolumn{7}{|l|}{ Household income } \\
\hline Low & reference & 0.948 & & & & \\
\hline Middle & 0.939 (0.197), 0.637-1.382 & 0.748 & & & & \\
\hline High & 0.979 (0.195), $0.668-1.434$ & 0.914 & & & & \\
\hline
\end{tabular}

2, Variable removed: District level SES; 3, Variable removed: Gender; 4, Variable removed: Distance to intervention sites; 5 , Variable removed: Employment status. 
When performing multivariate regression, five models were calculated using backward stepwise selection. The first model (step 1) included all predictors that showed noticeable differences in the HRs in the univariate model, such as community, intervention group, level of education, subjective health status, employment status, district level SES, and distance to study sites. The variable "Neighborhood setting" was taken out of the multivariate model due to its mathematical correlation (sum of) with the factor "Community". A correlation heat map of relevant variables is provided in the Supplementary in Figure S1. Contrary to the univariate model, the influence of the ecological factors (district level SES and distance to intervention) sites was no longer significant when controlling for the other variables in the analysis. On the other hand, self-reported health appeared to be a relevant determinant in the multivariate model $(p<0.01)$.

After stepwise exclusion of all non-significant $(p \geq 0.05)$ factors, four variables remained in the final model (step 5), namely community $(p<0.05)$, intervention group $(p<0.01)$, level of education $(p<0.05)$ and subjective health status $(p<0.01)$ (see Table 3$)$. Compared with the basic model, when other factors (district level SES, gender, distance to study sites and employment status) were removed, the final model revealed no severe changes with respect to the predictors, except for marginal improvements in the model significance levels. In conclusion, being randomized to CG was a significant predictor for a low HR of dropping out $(p<0.05)$. For IG2, the HR to leave the program before study completion was 2.7 times higher compared with CG (HR = 2.666, 95\% CI 1.737-4.093, $p<0.01)$. The greatest risk of dropout occurred for participants from the community Vahr $(\mathrm{HR}=1.803$ 95\% CI 1.155-2.815, $p<0.01)$. Being highly educated reduced the risk of dropout by $33 \%$ compared with those with low or moderate educational levels $(\mathrm{HR}=0.674$, $95 \%$, CI $0.448-0.931, p<0.1)$. Furthermore, self-reported less good or poor health increased the risk of leaving the study before completion by about 2.6 times compared with those that reported excellent or very good health $(\mathrm{HR}=2.644,95 \% \mathrm{CI} 1.590-4.396), p<0.01)$.

\subsection{Attendance in Weekly Onsite Classes}

Figure 6 presents the attendance rates of 10 weekly on-site classes (week two to 11 of the study) for three different groups in the community of Burglesum based on the expected number of attenders (those who had not dropped out of the study before the next class). Those who left the study before the first or after the 10th class were not included. Considering all communities, on average, the attendance rate decreased by almost one half $(46.4 \%)$ in the second week compared to the first. The level of attendance varied between the communities (Supplementary Figure S2).

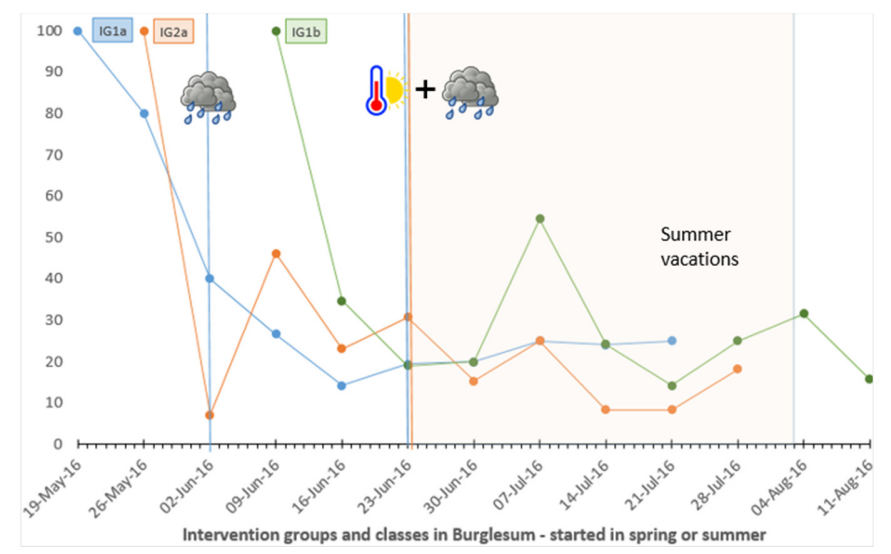

Figure 6. Weather expositions and holiday periods by days of class meeting and rate of expected attenders in different groups in the community Burglesum. Note: rainfall $>151 / \mathrm{m}^{2}$, of temperature $>30$. IG1a: web-based intervention with subjective PA self-monitoring, first group, IG1b: web-based intervention with subjective PA self-monitoring, second group, IG2a: web-based intervention with subjective and objective PA self-monitoring, first (only) group. 
The analysis of the extracted weather data yielded only a few days with significant weather exposures, for the period under consideration, of which the majority were wind exposures (affecting 19 class days within 11 different groups) (Supplementary Table S1). Nevertheless, the descriptive results, including holiday periods, revealed no clear trend regarding the association with attendance (further illustrations can be found in the Supplementary Figure S3).

\section{Discussion}

This article addresses the need to increase participation and retention in PA interventions, including attendance in weekly onsite PA classes among older adults, taking into account a range of potentially influencing factors based on a social ecological approach. Although the impact of ecological factors has been formulated as the initial key interest in response to the research gap, such an analysis would fail without considering individual and organizational factors. The findings from this study are discussed below in the context of existing evidence.

\subsection{Principal Findings}

In general, participation rates in our study were comparable to findings of a systematic review $(7 \%$ versus $9 \%)(86)$. Seven percent $(n=589)$ of the contacted and voluntarily registered older adults $(n=8474)$ participated in the study and were randomly allocated to one of two intervention groups or a delayed control group. In total, retention in our study was somewhat lower than in those included in a previous systematic review $(69 \%$ versus $80 \%)$ [84]. Nevertheless, varying attrition rates have been reported in the past, ranging from $22 \%$ to $76 \%$ for exercise interventions [93] and $0 \%$ to $62 \%$ for web-based PA interventions [94], which support previous findings characterizing e-health interventions as those with high dropout rates [10,95].

\subsection{Individual-Level Factors Associated with Participation and Dropout}

In line with previous research [96], we found that individuals who were older and not employed were more likely to participate and also to complete the study. This could be because adults who are not working have greater availability and flexibility regarding scheduling than younger and non-working ones [38]. Similar to former research, we found men to be less likely to participate $[29,30,94]$, but for those who did, there were indications $(p<0.1)$ that they appeared to remain in the study longer than women [12]. Regarding e-health interventions, some research suggests that men generally have more positive attitudes and self-efficacy expectations towards new technology than women and, thus, are more attracted by interventions based on technical devices [97]. In addition, our results support those of other studies revealing that being less healthy is linked to attrition $[23,26,37]$. In contrast to existing studies, we found a slightly higher proportion of low or moderately educated participants in our sample but, as identified by earlier research [26,37], proportionally higher educated participants completed the intervention. This may reflect the fact that awareness and understanding of the role of PA for health issues affects adherence to interventions.

Our analysis did not reveal age and household income as significant $(<0.05)$ predictors for dropout from the study, while other studies did [25,26,37]. However, the results on household income are difficult to compare, as we used the need-weighted income per capita for Germany as a basis, which is not necessarily transferable to other countries.

\subsection{Ecological Predictors Associated with Response, Participation and Dropout}

In line with socio-ecological approaches, this study considered a number of factors that might contribute to a better understanding of (non-)participation behavior by looking beyond the individual level. For example, those of the physical and social environment, as well as those at the organizational level. 
We found the largest non-response among individuals living in districts with very high community SES levels. At the same time, we found low district level SES to be significantly associated with remaining in the study, while other studies identified the highest dropout rates among participants living in areas with a lower SES [23]. Another finding of our study was that participants who lived in suburban areas were less likely to leave the study in contrast to those residing in urban areas. It can be assumed that these participants tend to commute by car, as former studies suggest $[98,99]$, and accessibility therefore is less of a barrier. Another explanation, supported by a recent systematic review, could be the limited supply of PA programs and classes in suburban areas and therefore the need to take advantage of existing ones, even with greater individual efforts [50]. However, this contradicts findings of a Canadian study identifying reduced participation in activities among older adults residing in car-dependent neighborhoods, such as suburbs [59]. One has to take in mind, that the typical environment looks different in Canada and Germany with the current study conducted in a more nearby assembly which might ease the retainment in the study.

Regarding accessibility, there were indications for the impact of proximity in our study when considering a community with a large distance to the study site (where the baseline assessment took place) and a high dropout rate during the week of the assessment. In addition, we found that participants with high proximities to study sites remained in the program longer compared with those with the smaller and the greatest distances. This is not consistent with other study findings emphasizing the benefit of close proximities $[54,55]$. These differences may be seen as an effect of the individual effort required to get to the site [38], not only the mere distance.

In our study, participation and dropout rates varied depending on the community that participants resided in. However, it is important to note that the differences are not solely determined by the ecological factors studied. Our findings and the remaining predictors in the final model of the Cox regression could be an indication for the high impact of differing program factors, which became already obvious in previous studies $[71,100]$. These may include the perception of and experience with intervention facilities, time slots (for the study assessment and/or the intervention classes), as well as the personality and professionalism of the assigned leaders of the onsite classes, which were not systematically assessed in our study, but in previous research $[16,17]$, and which may have differed by community in our study.

\subsection{Factors Associated with Recruitment and Study Design}

Recruitment of volunteers has long been a concern of research, as volunteers often differ from the general population in ways that are directly related to the study outcomes, as well as to participation and retention $[23,29]$. As recruiting via media and events was only a secondary strategy for this study, the proportion of individuals calling the team up to participate in the study was only $30 \%$. Although individuals who contacted the study team themselves to participate are assumed to be more motivated and committed to the study, which led to lower attrition rates in the past [10,23], we found no significant differences for volunteers leaving the study before the end compared to contacted individuals.

In addition to individual and ecological factors, characteristics of the intervention itself may affect dropout [96]. According to Eysenbach, attrition might also be the result of a wrong or mismatched intervention treatment [10]. In our study, randomization to intervention groups as a factor related to the study design appeared to be a significant predictor for retention. We identified higher dropout rates in the IGs than in the CG. This difference may be explained by the fact that participants in waitlisted groups are typically more motivated to stay in the study, due to the expectation of receiving the program afterwards [10]. Furthermore, they are probably less likely to discontinue due to time constraints, because they do not receive appointments interfering with that. In addition, the discrepancy between IG1 and IG2 regarding dropout supports technology-based causes (such as lack of technical competences or experiences) identified earlier [76,101]. 


\subsection{Impact of Season, Weather Conditions and Holiday Periods}

In line with a previous review identifying certain seasons as barriers for PA [63], this factor appeared to have an impact on participation in our study. The higher dropout rates in our study that occurred in summer (versus winter) may support findings from previous research, indicating that individuals tend to use their spare time for more personal outdoor activities during the warm and sunny months [68]. However, this is contradicted by findings from qualitative studies with participants stating that they prefer courses in summer months as they do not occur or finish after dark [102]. Consequently, there should be a varying offer covering these different needs at best.

However, we found no clear evidence regarding poor and extreme weather to transfer the findings of that review to the results obtained for attendance in onsite classes in our study. One reason could be that the cutoffs for the weather expositions were somewhat inappropriate and that a differing classification would have yielded other results. In our study, the public holidays and school breaks revealed no obvious effects on class attendance. Probably, PA interventions like this might act as a substitute for the more limited access to public sports clubs and the reduced number of exercise classes during vacation periods.

Similar to our study, former research found ecological factors to explain less of the variations compared to individual-level factors [103], which, however, does not mean that they require less attention during intervention planning. Regarding retention, it is conceivable that for those who once decided to participate, ecological factors, such as distances, no longer play a role. Rather, it appears to be that individual-level factors, such as demands of the participants, or details of the program itself, which have been suggested to be related to early dropout $[38,71,100]$, are more important. Research on the socioemotional selectivity theory has found emotional gratifications and support to be particularly important for older adults [104]. This might reflect the impact of the group composition itself as well as that of the group leadership for the attendance behavior towards the onsite classes.

Because emotional selection processes also seem to increase voluntary activities [105], future research might already take advantage of such findings in the early recruiting phase. Consideration should also be given as to how to appeal to different subgroups of the older adult population, such as those with low levels of education or low subjective health. This study found that there have been difficulties in engaging men in organized PA sessions, which confirms findings of previous research and have led to the development of older men only activities [102]. Within this study, there were greater numbers of finishers in groups with low requirements for technical skills. These challenges, as well as that of motivating the uninterested individuals, will need to be addressed in a revision of the image and design of the intervention in the future.

\subsection{Strengths and Limitations}

This study is among the first to examine ecological factors, such as proximities, weather conditions, and socioeconomic status at the neighborhood level, in a German context to explain inequalities regarding participation and retention in a PA intervention. To the best of our knowledge, there is no other study to date that has investigated study dropout using GIS based network analysis. A further strength is the variety of analyzed indicators. In particular, we used both geocoded data and open data, such as street network data and weather data, and demonstrated how GIS analysis could be used to evaluate access. The detailed documentation of study dropout, as well as the sufficient number of study participants, enabled us to perform survival analyses for various subgroups.

However, some limitations need to be considered. First, we enrolled individuals with minimal comorbidities and rather independent individuals regarding their activities of daily living, which does not adequately reflect reality. In addition, the composition of our study sample suggests that predominantly active older adults are particularly attracted to PA programs, which is a well-known problem in recruiting participants for health promotion research, suggesting a selection bias. Appropriate strategies are still lacking. Furthermore, 
some of the respondents had to be excluded from the study because they did not meet the inclusion criterion of owning a PC or did not have access to the internet. This may have led to the exclusion or insufficient recruitment of socioeconomically disadvantaged older adults and may have finally reduced the representativeness of the study sample.

Second, as we did not track individual attendance in group meetings, this part of the analysis could only be performed at a group level. Third, due to missing values for age in the contacted sample (about 50\%), no conclusions can be drawn regarding age as a potential correlate of response. Fourth, for this quantitative analysis, we disregarded the self-reported reasons for withdrawal. This was partly because many participants did not provide any specific information, and because factors might overlap. Finally, the modifiable areal unit problem (MAUP) is a source of bias in research of spatial phenomena, therefore also in this study. It states that results are affected by the shape and scale of the aggregation unit (e.g., districts) [106].

\section{Conclusions}

Identifying different predictors of older adults' participation and retention can help improve future interventions for the promotion of healthy aging. Our results suggest that a key element is knowledge of the composition and needs of the targeted group. As older adults are a very heterogeneous group, tailoring PA interventions more accurately according to individual level determinants (including perceived health conditions and levels of education) may prevent high dropout.

Because program-related characteristics also appear to be of great importance, they might also already be taken into account during the planning stage.

However, further research is needed to obtain a robust conclusion on the influence of environmental factors on participation and retention in health interventions for older adults, such as programs for PA promotion. Improvements in the quality of the existing data and the measurement methods (e.g., cut offs for proximities and weather expositions) might lead to clearer results in the future.

Supplementary Materials: The following supporting information can be downloaded at: https: / / www.mdpi.com/article/10.3390/ijerph19063190/s1, Correlation Heat Map and descriptive presentations of weekly class attendance and weather expositions. Figure S1: Heat Map of correlation coefficients (Spearman's rho). Interpretation: $0=$ none, $0.1-0.2=$ poor, $0.3-0.5=$ fair, $0.6-0.7=$ moderate, 0.8-0.9 very strong, 1 = perfect [107]. Bold type $=$ Correlation is significant at the 0.01 level (2-tailed). $\mathrm{NE}=$ Neighborhood. Figure S2: Descriptive of 10 weeks' class attendance rates. Figure S3: Weather expositions and holiday periods by days of class meeting and rate of expected attenders in different groups and communities. Note: rainfall $>151 / \mathrm{m}^{2}, 8$ temperature $>30$ : wind speed $>7$, IG1a: web-based intervention with subjective PA self-monitoring, first group, IG1b: web-based intervention with subjective PA self-monitoring, second group, IG2a: web-based intervention with subjective and objective PA self-monitoring, first (only) group. Table S1: Number and type of weather expositions by different groups and communities. Note: ${ }^{*}$ The number of groups in each community varied according to the total number of participants in that community. The target group size was about 20 participants. ${ }^{* *}$ Those who left the study before the first class were not included.

Author Contributions: M.P. conceptualized the manuscript and method, curated and analyzed the data, drafted the original manuscript, and visualized the results (maps and figures). T.R., F.W. and C.R.P. have made substantial contributions to the manuscript. S.L., C.V.-R. and C.R.P. conceptualized the study design and acquired the study funding. All authors have read and agreed to the published version of the manuscript.

Funding: The study is conducted as part of the "AEQUIPA—Physical activity and health equity: primary prevention for healthy ageing" project, a regional prevention research project and network funded by the German Federal Ministry of Education and Research (grant number: 01EL1422A, 01EL1822C, 01EL1822F, 01EL1822I). The funder was not involved in the design of the study, in the collection, analysis, and interpretation of data, or in writing the manuscript. The content of this 
article reflects only the authors' views and the funder is not liable for any use that may be made of the information contained therein.

Institutional Review Board Statement: Ethical approval for conducting this study was obtained by the Technical University of Chemnitz, Faculty of Behavioral and Social Sciences, on 14 July 2015.

Informed Consent Statement: All participants were informed about the study during the initial telephone interviews and an introductory face-to-face briefing session and provided informed consent.

Data Availability Statement: The data presented in this study are not publicly available due to privacy issues, including the possibility of re-identification.

Acknowledgments: The authors would like to thank Beate Schuette, the study nurse in the study, for her effort during the recruitment and data collection phases of the study.

Conflicts of Interest: The authors declare no conflict of interest.

\section{References}

1. Warburton, D.E.; Nicol, C.W.; Bredin, S.S. Health benefits of physical activity: The evidence. CMAJ 2006, 174, 801-809. [CrossRef] [PubMed]

2. Hupin, D.; Roche, F.; Gremeaux, V.; Chatard, J.C.; Oriol, M.; Gaspoz, J.M.; Barthelemy, J.C.; Edouard, P. Even a low-dose of moderate-to-vigorous physical activity reduces mortality by $22 \%$ in adults aged $\geq 60$ years: A systematic review and meta-analysis. Br. J. Sport. Med. 2015, 49, 1262-1267. [CrossRef] [PubMed]

3. Barnett, D.W.; Barnett, A.; Nathan, A.; Van Cauwenberg, J.; Cerin, E. Built environmental correlates of older adults' total physical activity and walking: A systematic review and meta-analysis. Int. J. Behav. Nutr. Phys. Act. 2017, 14, 103. [CrossRef] [PubMed]

4. Reis, R.S.; Salvo, D.; Ogilvie, D.; Lambert, E.V.; Goenka, S.; Brownson, R.C.; Lancet Physical Activity Series 2 Executive Committee. Scaling up physical activity interventions worldwide: Stepping up to larger and smarter approaches to get people moving. Lancet 2016, 388, 1337-1348. [CrossRef]

5. Pfeifer, K.; Rütten, A. Nationale Empfehlungen für Bewegung und Bewegungsförderung. Gesundheitswesen 2017, 79, S2-S3. [CrossRef]

6. Finger, J.D.; Mensink, G.; Lange, C.; Manz, K. Gesundheitsfördernde körperliche Aktivität in der Freizeit bei Erwachsenen in Deutschland. J. Health Monit. 2017, 2, 37-44.

7. WHO. Global Recommendations on Physical Activty for Health; WHO: Geneva, Switzerland, 2010. Available online: https://www. who.int/publications/i/item/9789241599979 (accessed on 18 February 2022).

8. Van Der Bij, A.K.; Laurant, M.G.; Wensing, M. Effectiveness of physical activity interventions for older adults: A review. Am. J. Prev. Med. 2002, 22, 120-133. [CrossRef]

9. Sully, B.G.; Julious, S.A.; Nicholl, J. A reinvestigation of recruitment to randomised, controlled, multicenter trials: A review of trials funded by two UK funding agencies. Trials 2013, 14, 1-9. [CrossRef]

10. Eysenbach, G. The law of attrition. J. Med. Internet Res. 2005, 7, e402. [CrossRef]

11. Wichmann, F.; Brand, T.; Gansefort, D.; Darmann-Finck, I. Ready to participate? Using qualitative data to typify older adults' reasons for (non-) participation in a physical activity promotion intervention. BMC Public Health 2019, 19, 1327. [CrossRef]

12. Guertler, D.; Vandelanotte, C.; Kirwan, M.; Duncan, M.J. Engagement and nonusage attrition with a free physical activity promotion program: The case of 10,000 steps Australia. J. Med. Internet Res. 2015, 17, e4339. [CrossRef] [PubMed]

13. Kaplan, R.M.; Atkins, C.J. Selective attrition causes overestimates of treatment effects in studies of weight loss. Addict. Behav. 1987, 12, 297-302. [CrossRef]

14. Martin, K.A.; Sinden, A.R. Who will stay and who will go? A review of older adults' adherence to randomized controlled trials of exercise. J. Aging Phys. Act. 2001, 9, 91-114. [CrossRef]

15. Gul, R.B.; Ali, P.A. Clinical trials: The challenge of recruitment and retention of participants. J. Clin. Nurs. 2010, 19, 227-233. [CrossRef] [PubMed]

16. Hawley-Hague, H.; Horne, M.; Campbell, M.; Demack, S.; Skelton, D.A.; Todd, C. Multiple levels of influence on older adults' attendance and adherence to community exercise classes. Gerontologist 2014, 54, 599-610. [CrossRef] [PubMed]

17. Killingback, C.; Tsofliou, F.; Clark, C. Older people's adherence to community-based group exercise programmes: A multiple-case study. BMC Public Health 2017, 17, 115. [CrossRef] [PubMed]

18. Carstensen, L.L. Evidence for a life-span theory of socioemotional selectivity. Curr. Dir. Psychol. Sci. 1995, 4, 151-156. [CrossRef]

19. Armitage, C.J.; Conner, M. Social cognition models and health behaviour: A structured review. Psychol. Health 2000, 15, 173-189. [CrossRef]

20. Sallis, J.F.; Cervero, R.B.; Ascher, W.; Henderson, K.A.; Kraft, M.K.; Kerr, J. An ecological approach to creating active living communities. Annu. Rev. Public Health 2006, 27, 297-322. [CrossRef]

21. Barton, H.; Grant, M. A health map for the local human habitat. J. R. Soc. Promot. Health 2006, 126, 252. [CrossRef]

22. Stokols, D. Translating social ecological theory into guidelines for community health promotion. Am. J. Health Promot. 1996, 10, 282-298. [CrossRef] [PubMed] 
23. Jancey, J.; Lee, A.; Howat, P.; Clarke, A.; Wang, K.; Shilton, T. Reducing attrition in physical activity programs for older adults. J. Aging Phys. Act. 2007, 15, 152-165. [CrossRef] [PubMed]

24. Rhodes, R.E.; Martin, A.D.; Taunton, J.E.; Rhodes, E.C.; Donnelly, M.; Elliot, J. Factors associated with exercise adherence among older adults. Sport. Med. 1999, 28, 397-411. [CrossRef] [PubMed]

25. Chatfield, M.D.; Brayne, C.E.; Matthews, F.E. A systematic literature review of attrition between waves in longitudinal studies in the elderly shows a consistent pattern of dropout between differing studies. J. Clin. Epidemiol. 2005, 58, 13-19. [CrossRef]

26. Van Beijsterveldt, C.; Van Boxtel, M.; Bosma, H.; Houx, P.; Buntinx, F.; Jolles, J. Predictors of attrition in a longitudinal cognitive aging study: The Maastricht Aging Study (MAAS). J. Clin. Epidemiol. 2002, 55, 216-223. [CrossRef]

27. Brassington, G.S.; Atienza, A.A.; Perczek, R.E.; DiLorenzo, T.M.; King, A.C. Intervention-related cognitive versus social mediators of exercise adherence in the elderly. Am. J. Prev. Med. 2002, 23, 80-86. [CrossRef]

28. McAuley, E.; Jerome, G.J.; Elavsky, S.; Marquez, D.X.; Ramsey, S.N. Predicting long-term maintenance of physical activity in older adults. Prev. Med. 2003, 37, 110-118. [CrossRef]

29. Chinn, D.J.; White, M.; Howel, D.; Harland, J.O.; Drinkwater, C.K. Factors associated with non-participation in a physical activity promotion trial. Public Health 2006, 120, 309-319. [CrossRef]

30. Lakerveld, J.; IJzelenberg, W.; Van Tulder, M.W.; Hellemans, I.M.; Rauwerda, J.A.; Van Rossum, A.C.; Seidell, J.C. Motives for (not) participating in a lifestyle intervention trial. BMC Med. Res. Methodol. 2008, 8, 17. [CrossRef]

31. Picorelli, A.M.; Pereira, L.S.; Pereira, D.S.; Felício, D.; Sherrington, C. Adherence to exercise programs for older people is influenced by program characteristics and personal factors: A systematic review. J. Physiother. 2014, 60, 151-156. [CrossRef]

32. Resnick, B.; Spellbring, A.M. Understanding what motivates older adults to exercise. J. Gerontol. Nurs. 2000, 26, 34-42. [CrossRef]

33. Manaf, H. Barriers to participation in physical activity and exercise among middle-aged and elderly individuals. Singap. Med. J. 2013, 54, 581-586.

34. Forsat, N.D.; Palmowski, A.; Palmowski, Y.; Boers, M.; Buttgereit, F. Recruitment and retention of older people in clinical research: A systematic literature review. J. Am. Geriatr. Soc. 2020, 68, 2955-2963. [CrossRef]

35. Elzen, H.; Slaets, J.P.; Snijders, T.A.; Steverink, N. Do older patients who refuse to participate in a self-management intervention in the Netherlands differ from older patients who agree to participate? Aging Clin. Exp. Res. 2008, 20, 266-271. [CrossRef]

36. Bentley, C.L.; Powell, L.; Potter, S.; Parker, J.; Mountain, G.A.; Bartlett, Y.K.; Farwer, J.; O'Connor, C.; Burns, J.; Cresswell, R.L. The use of a smartphone app and an activity tracker to promote physical activity in the management of chronic obstructive pulmonary disease: Randomized controlled feasibility study. JMIR MHealth uHealth 2020, 8, e16203. [CrossRef]

37. Jacomb, P.A.; Jorm, A.F.; Korten, A.E.; Christensen, H.; Henderson, A.S. Predictors of refusal to participate: A longitudinal health survey of the elderly in Australia. BMC Public Health 2002, 2, 4. [CrossRef]

38. Wichmann, F.; Pischke, C.R.; Jurgens, D.; Darmann-Finck, I.; Koppelin, F.; Lippke, S.; Pauls, A.; Peters, M.; Voelcker-Rehage, C.; Muellmann, S. Requirements for (web-based) physical activity interventions targeting adults above the age of 65 years-qualitative results regarding acceptance and needs of participants and non-participants. BMC Public Health 2020, 20, 907. [CrossRef]

39. Macintyre, S.; Ellaway, A.; Cummins, S. Place effects on health: How can we conceptualise, operationalise and measure them? Soc. Sci. Med. 2002, 55, 125-139. [CrossRef]

40. King, A.C.; Blair, S.N.; Bild, D.E.; Dishman, R.K.; Dubbert, P.M.; Marcus, B.H.; Oldridge, N.B.; Paffenbarger, R.S.; Powell, K.E.; Yeager, K.K. Determinants of physical activity and interventions in adults. Med. Sci. Sport. Exerc. 1992, 24, S221-S236. [CrossRef]

41. Levasseur, M.; Généreux, M.; Bruneau, J.-F.; Vanasse, A.; Chabot, É.; Beaulac, C.; Bédard, M.-M. Importance of proximity to resources, social support, transportation and neighborhood security for mobility and social participation in older adults: Results from a scoping study. BMC Public Health 2015, 15, 1-19. [CrossRef]

42. Humpel, N.; Owen, N.; Leslie, E. Environmental factors associated with adults' participation in physical activity: A review. Am. J. Prev. Med. 2002, 22, 188-199. [CrossRef]

43. Owen, N.; Humpel, N.; Leslie, E.; Bauman, A.; Sallis, J.F. Understanding environmental influences on walking: Review and research agenda. Am. J. Prev. Med. 2004, 27, 67-76. [CrossRef]

44. Kamphuis, C.B.M.; Van Lenthe, F.J.; Giskes, K.; Huisman, M.; Brug, J.; Mackenbach, J.P. Socioeconomic Status, Environmental and Individual Factors, and Sports Participation. Med. Sci. Sport. Exerc. 2008, 40, 71-81. [CrossRef]

45. Knechel, N.A. The challenges of enrolling older adults into intervention studies. Yale J. Biol. Med. 2013, 86, 41.

46. Martinez, I.L.; Kim, K.; Tanner, E.; Fried, L.P.; Seeman, T. Ethnic and class variations in promoting social activities among older adults. Act. Adapt. Aging 2009, 33, 96-119. [CrossRef]

47. Franke, T.; Sims-Gould, J.; Chaudhury, H.; Winters, M.; McKay, H. Re-framing mobility in older adults: An adapted comprehensive conceptual framework. Qual. Res. Sport Exerc. Health 2020, 12, 336-349. [CrossRef]

48. Boyette, L.W.; Lloyd, A.; Boyette, J.E.; Watkins, E.; Furbush, L.; Dunbar, S.B.; Brandon, L.J. Personal characteristics that influence exercise behavior of older adults. J. Rehabil. Res. Dev. 2002, 39, 95-104.

49. Van Lenthe, F.J.; Brug, J.; Mackenbach, J.P. Neighbourhood inequalities in physical inactivity: The role of neighbourhood attractiveness, proximity to local facilities and safety in the Netherlands. Soc. Sci. Med. 2005, 60, 763-775. [CrossRef]

50. Liljas, A.E.; Walters, K.; Jovicic, A.; Iliffe, S.; Manthorpe, J.; Goodman, C.; Kharicha, K. Strategies to improve engagement of 'hard to reach'older people in research on health promotion: A systematic review. BMC Public Health 2017, 17, 349. [CrossRef]

51. Wahl, H.-W.; Lang, F.R. Aging in context across the adult life course: Integrating physical and social environmental research perspectives. Annu. Rev. Gerontol. Geriatr. 2003, 23, 1-33. 
52. Odierna, D.H.; Bero, L.A. Retaining participants in outpatient and community-based health studies: Researchers and participants in their own words. SAGE Open 2014, 4, 2158244014554391. [CrossRef]

53. Cherubini, A.; Signore, S.D.; Ouslander, J.; Semla, T.; Michel, J.P. Fighting against age discrimination in clinical trials. J. Am. Geriatr. Soc. 2010, 58, 1791-1796. [CrossRef]

54. Roigk, P.; Kampe, K.; Rapp, K.; Rupp, K.; Pfeiffer, K. Teilnahmebereitschaft und Adhärenz von Teilnehmern an “Trittsicher"Bewegungskursen. Physioscience 2019, 15, 53-62. [CrossRef]

55. Belza, B.; Chiang, K.-C.; Seman, L.; Tsai, J.H.-C. Peer Reviewed: “It Is Our Exercise Family”: Experiences of Ethnic Older Adults in a Group-Based Exercise Program. Prev. Chronic Dis. 2008, 5, A05.

56. Knox, P.L. The intraurban ecology of primary medical care: Patterns of accessibility and their policy implications. Environ. Plan. A 1978, 10, 415-435. [CrossRef]

57. Basche, M.; Barón, A.E.; Eckhardt, S.G.; Balducci, L.; Persky, M.; Levin, A.; Jackson, N.; Zeng, C.; Vranas, P.; Steiner, J.F. Barriers to enrollment of elderly adults in early-phase cancer clinical trials. J. Oncol. Pract. 2008, 4, 162-168. [CrossRef]

58. Sharma, S.K.; Tobin, J.D.; Brant, L.J. Factors affecting attrition in the Baltimore Longitudinal Study of Aging. Exp. Gerontol. 1986, 21, 329-340. [CrossRef]

59. Farber, S.; Páez, A.; Mercado, R.G.; Roorda, M.; Morency, C. A time-use investigation of shopping participation in three Canadian cities: Is there evidence of social exclusion? Transportation 2011, 38, 17-44. [CrossRef]

60. Follmer, R.; Gruschwitz, D.; Jesske, B.; Quandt, S.; Lenz, B.; Nobis, C.; Mehlin, M. Mobilität in Deutschland 2008: Ergebnisbericht; Technical Report; Federal Ministry for Transport, Building and Urban Development, INFAS, DLR: Berlin, Germany, 2010.

61. Van den Berg, P.; Arentze, T.; Timmermans, H. Estimating social travel demand of senior citizens in the Netherlands. J. Transp. Geogr. 2011, 19, 323-331. [CrossRef]

62. Scheiner, J. Interrelations between travel mode choice and trip distance: Trends in Germany 1976-2002. J. Transp. Geogr. 2010, 18, 75-84. [CrossRef]

63. Tucker, P.; Gilliland, J. The effect of season and weather on physical activity: A systematic review. Public Health 2007, 121, 909-922. [CrossRef]

64. Díaz, J.; Garcia, R.; De Castro, F.V.; Hernández, E.; López, C.; Otero, A. Effects of extremely hot days on people older than 65 years in Seville (Spain) from 1986 to 1997. Int. J. Biometeorol. 2002, 46, 145-149.

65. Clarke, P.J.; Yan, T.; Keusch, F.; Gallagher, N.A. The Impact of Weather on Mobility and Participation in Older U.S. Adults. Am. J. Public Health 2015, 105, 1489-1494. [CrossRef]

66. Böcker, L.; Priya Uteng, T.; Liu, C.; Dijst, M. Weather and daily mobility in international perspective: A cross-comparison of Dutch, Norwegian and Swedish city regions. Transp. Res. Part D Transp. Environ. 2019, 77, 491-505. [CrossRef]

67. Böcker, L.; Dijst, M.; Prillwitz, J. Impact of everyday weather on individual daily travel behaviours in perspective: A literature review. Transp. Rev. 2013, 33, 71-91. [CrossRef]

68. Tu, W.; Stump, T.E.; Damush, T.M.; Clark, D.O. The effects of health and environment on exercise-class participation in older, urban women. J. Aging Phys. Act. 2004, 12, 480-496. [CrossRef]

69. Chan, C.B.; Ryan, D.A.; Tudor-Locke, C. Relationship between objective measures of physical activity and weather: A longitudinal study. Int. J. Behav. Nutr. Phys. Act. 2006, 3, 21. [CrossRef]

70. Tulloch, H.; Sweet, S.N.; Fortier, M.; Capstick, G.; Kenny, G.P.; Sigal, R.J. Exercise facilitators and barriers from adoption to maintenance in the diabetes aerobic and resistance exercise trial. Can. J. Diabetes 2013, 37, 367-374. [CrossRef]

71. Bogart, L.M.; Uyeda, K. Community-based participatory research: Partnering with communities for effective and sustainable behavioral health interventions. Health Psychol. 2009, 28, 391-393. [CrossRef]

72. Burton, E.; Hill, A.-M.; Pettigrew, S.; Lewin, G.; Bainbridge, L.; Farrier, K.; Airey, P.; Hill, K.D. Why do seniors leave resistance training programs? Clin. Interv. Aging 2017, 12, 585. [CrossRef]

73. Dolansky, M.A.; Stepanczuk, B.; Charvat, J.M.; Moore, S.M. Women's and men's exercise adherence after a cardiac event: Does age make a difference? Res. Gerontol. Nurs. 2010, 3, 30-38. [CrossRef]

74. Forberger, S.; Bammann, K.; Bauer, J.; Boll, S.; Bolte, G.; Brand, T.; Hein, A.; Koppelin, F.; Lippke, S.; Meyer, J.; et al. How to Tackle Key Challenges in the Promotion of Physical Activity among Older Adults (65+): The AEQUIPA Network Approach. Int. J. Environ. Res Public Health 2017, 14, 379. [CrossRef]

75. Muellmann, S.; Bragina, I.; Voelcker-Rehage, C.; Rost, E.; Lippke, S.; Meyer, J.; Schnauber, J.; Wasmann, M.; Toborg, M.; Koppelin, F. Development and evaluation of two web-based interventions for the promotion of physical activity in older adults: Study protocol for a community-based controlled intervention trial. BMC Public Health 2017, 17, 512. [CrossRef]

76. Muellmann, S.; Buck, C.; Voelcker-Rehage, C.; Bragina, I.; Lippke, S.; Meyer, J.; Peters, M.; Pischke, C.R. Effects of two web-based interventions promoting physical activity among older adults compared to a delayed intervention control group in Northwestern Germany: Results of the PROMOTE community-based intervention trial. Prev. Med. Rep. 2019, 15, 100958. [CrossRef]

77. Gansefort, D.; Brand, T.; Princk, C.; Zeeb, H. Community readiness for the promotion of physical activity in older adults-A cross-sectional comparison of rural and urban communities. Int. J. Environ. Res. Public Health 2018, 15, 453. [CrossRef]

78. Climate Data Center. Data Portal. Available online: https://cdc.dwd.de/portal/ (accessed on 18 February 2022).

79. Schulferien.org. Schulferien, Kalender, Feiertage. Available online: https://www.schulferien.org/deutschland/ (accessed on 18 February 2022).

80. Geyer, S. Einzelindikator oder index? Masse sozialer Differenzierung im Vergleich. Gesundheitswesen 2008, 70, 281-288. [CrossRef] 
81. Kukulska, A.; Salata, T.; Cegielska, K.; Szylar, M. Methodology of evaluation and correction of geometric data topology in QGIS software. Acta Sci. Polonorum. Form. Circumiectus 2018, 17, 137-150. [CrossRef]

82. Peters, M.; Muellmann, S.; Christianson, L.; Stalling, I.; Bammann, K.; Drell, C.; Forberger, S. Measuring the association of objective and perceived neighborhood environment with physical activity in older adults: Challenges and implications from a systematic review. Int. J. Health Geogr. 2020, 19, 47. [CrossRef]

83. Villanueva, K.; Knuiman, M.; Nathan, A.; Giles-Corti, B.; Christian, H.; Foster, S.; Bull, F. The impact of neighborhood walkability on walking: Does it differ across adult life stage and does neighborhood buffer size matter? Health Place 2014, 25, 43-46. [CrossRef]

84. Davern, M.; Gunn, L.; Whitzman, C.; Higgs, C.; Giles-Corti, B.; Simons, K.; Villanueva, K.; Mavoa, S.; Roberts, R.; Badland, H. Using spatial measures to test a conceptual model of social infrastructure that supports health and wellbeing. Cities Health 2017, 1, 194-209. [CrossRef]

85. Buck, C.; Dreger, S.; Pigeot, I. Anonymisation of address coordinates for microlevel analyses of the built environment: A simulation study. BMJ Open 2015, 5, e006481. [CrossRef]

86. DWD. Warnkriterien. Available online: https://www.dwd.de/DE/wetter/warnungen_aktuell/kriterien/warnkriterien.html? nn=508722 (accessed on 18 February 2022).

87. Bundesamt, S. Demographische Standards Ausageb 2016 Statistik und Wissenschaft; Statistisches Bundesamt: Wiesbaden, Germany, 2016; Volume 17.

88. Bertelsmann Stiftung, Sozialplanung Für Senioren. Fragebogen TF 1 Demografische und Sozio-Kulturelle Daten. Available online: http:/ / www.sozialplanung-senioren.de/frageboegen-bausteine/frageboegen-nach-themenfeldern/index.html? L=0\% $2 \mathrm{~F} \% 2 \mathrm{~F} \% 2 \mathrm{~F} \% 2 \mathrm{~F} \% 27 \mathrm{tyl}$ (accessed on 18 February 2022).

89. Robert-Koch-Institut. Studie zur Gesundheit Erwachsener in Deutschland (DEGS): Gesundheitsfragebogen ab 65 Jahren; Bundesministerium für Gesundheit und Robert Koch-Institut: Berlin, Germany, 2009.

90. Boehle, M. Armutsmessung mit dem Mikrozensus: Methodische Aspekte und Umsetzung für Querschnitts-und Trendanalysen; GESIS Papers 2015/16; GESIS-Leibniz-Institut für Sozialwissenschaften: Mannheim, Germany, 2015.

91. Morfeld, M.; Kirchberger, I.; Bullinger, M. SF-36 Fragebogen zum Gesundheitszustand: Deutsche Version des Short Form-36 Health Survey; Hogrefe: Göttingen, Germany, 2011.

92. IBM Corp. IBM SPSS Statistics for Windows; IBM Corp.: Armonk, NY, USA, 2017.

93. Schmidt, J.A.; Gruman, C.; King, M.B.; Wolfson, L.I. Attrition in an exercise intervention: A comparison of early and later dropouts. J. Am. Geriatr. Soc. 2000, 48, 952-960. [CrossRef]

94. Davies, C.A.; Spence, J.C.; Vandelanotte, C.; Caperchione, C.M.; Mummery, W.K. Meta-analysis of internet-delivered interventions to increase physical activity levels. Int. J. Behav. Nutr. Phys. Act. 2012, 9, 52. [CrossRef]

95. Ryan, C.; Bergin, M.; Wells, J.S.G. Theoretical Perspectives of Adherence to Web-Based Interventions: A Scoping Review. Int. J. Behav. Med. 2018, 25, 17-29. [CrossRef]

96. Verheijden, M.W.; Jans, M.P.; Hildebrandt, V.H.; Hopman-Rock, M. Rates and determinants of repeated participation in a web-based behavior change program for healthy body weight and healthy lifestyle. J. Med. Internet Res. 2007, 9, e1. [CrossRef]

97. Cai, Z.; Fan, X.; Du, J. Gender and attitudes toward technology use: A meta-analysis. Comput. Educ. 2017, 105, 1-13. [CrossRef]

98. Rosenbloom, S. Sustainability and automobility among the elderly: An international assessment. Transportation 2001, 28, 375-408. [CrossRef]

99. Rosenbloom, S.; Waldorf, B. Older travelers: Does place or race make a difference? Transp. Res. Circ. 2001, E-C026, 103-120.

100. Warren-Findlow, J.; Prohaska, T.R.; Freedman, D. Challenges and opportunities in recruiting and retaining underrepresented populations into health promotion research. Gerontologist 2003, 43, 37-46. [CrossRef]

101. Oenema, A.; Brug, J.; Dijkstra, A.; de Weerdt, I.; de Vries, H. Efficacy and use of an internet-delivered computer-tailored lifestyle intervention, targeting saturated fat intake, physical activity and smoking cessation: A randomized controlled trial. Ann. Behav. Med. 2008, 35, 125-135. [CrossRef]

102. Boulton, E.R.; Horne, M.; Todd, C. Multiple influences on participating in physical activity in older age: Developing a social ecological approach. Health Expect. 2018, 21, 239-248. [CrossRef]

103. Giles-Corti, B.; Donovan, R.J. The relative influence of individual, social and physical environment determinants of physical activity. Soc. Sci. Med. 2002, 54, 1793-1812. [CrossRef]

104. Bartsch, A. As time goes by: What changes and what remains the same in entertainment experience over the life span? J. Commun. 2012, 62, 588-608. [CrossRef]

105. Hendricks, J.; Cutler, S.J. Volunteerism and socioemotional selectivity in later life. J. Gerontol. Ser. B Psychol. Sci. Soc. Sci. 2004, 59, S251-S257. [CrossRef]

106. Wong, D.W.S. The modifiable areal unit problem (MAUP). In WorldMinds: Geographical Perspectives on 100 Problems; Springer: Dordrecht, The Netherlands, 2004; pp. 571-575.

107. Chan, Y. Biostatistics 104: Correlational analysis. Singapore Med. J. 2003, 44, 614-619. 